\title{
Intramolecular loop/tail interactions are essential for connexin 43-hemichannel activity
}

\author{
Raf Ponsaerts, ${ }^{*, 1}$ Elke De Vuyst, ${ }^{\ddagger}, 1$ Mauricio Retamal, ${ }^{\S}$ Catheleyne D’hondt,* \\ Dieter Vermeire, ${ }^{\dagger}$ Nan Wang, ${ }^{\ddagger}$ Humbert De Smedt, ${ }^{*}$ Pascale Zimmermann, ${ }^{\dagger}$ \\ Bernard Himpens, ${ }^{*}$ Johan Vereecke, ${ }^{*}$ Luc Leybaert, ${ }^{\ddagger, 2}$ and Geert Bultynck*,2,3 \\ *Laboratory of Molecular and Cellular Signaling, Department of Molecular Cell Biology, and \\ ${ }^{\dagger}$ Laboratory of Signal Integration in Cell Fate Decision, Department of Human Genetics, K.U. \\ Leuven, Leuven, Belgium; ${ }^{\dagger}$ Department of Basic Medical Sciences, Physiology Group, Faculty of \\ Medicine and Health Sciences, Ghent University, Ghent, Belgium; and ${ }^{\S}$ Clínica Alemana-Universidad \\ del Desarrollo, Laboratorio de Fisiología, Santiago, Chile
}

ABSTRACT Connexin-assembled gap junctions (GJs) and hemichannels coordinate intercellular signaling processes. Although the regulation of connexins in GJs has been well characterized, the molecular determinants controlling connexin-hemichannel activity are unresolved. Here we investigated the regulation of Cx43-hemichannel activity by actomyosin contractility and intracellular $\left[\mathrm{Ca}^{2+}\right]\left(\left[\mathrm{Ca}^{2+}\right]_{\mathrm{i}}\right)$ using plasma membrane-permeable TAT peptides (100 $\mu \mathrm{M})$ designed to interfere with interactions between the cytoplasmic loop (CL) and carboxy-terminal (CT) in primary bovine corneal endothelial cells and HeLa, C6 glioma, and Xenopus oocytes ectopically expressing Cx43. Peptides corresponding to the last $10 \mathrm{CT}$ aa (TAT-Cx43CT) prevented the inhibition of Cx43-hemichannel activity by contractility/high $\left[\mathrm{Ca}^{2+}\right]_{\mathrm{i}}$, whereas a reverse peptide (TAT-Cx43CTrev) did not. These effects were independent of zonula occludens-1, a cytoskeletal-associated Cx43-binding protein. In contrast, peptides corresponding to $\mathrm{CL}$ (TAT-L2) inhibited Cx43-hemichannel responses, whereas a mutant peptide $\left(\mathrm{TAT}-\mathrm{L} 2^{\mathrm{H} 126 \mathrm{~K} / \mathrm{I1} 130 \mathrm{~N}}\right)$ did not inhibit. In these assays, TAT-Cx43CT acted as a scaffold for TAT-L2 and vice versa, a finding supported by surface plasmon resonance measurements. Loop/tail interactions appeared essential for $\mathrm{Cx}$ 43-hemichannel activity, because TAT-Cx43CT restored the activity of nonfunctional hemichannels, consisting of either $\mathrm{Cx} 43$ lacking the C-terminal tail $\left(\mathrm{Cx}_{\mathbf{4}} 43^{\mathrm{M} 239}\right)$ or intact $\mathrm{C} \times 43$ ectopically expressed in Xenopus oocytes. We conclude that intramolecular loop/tail interactions control $\mathbf{C x 4 3 -}$ hemichannel activity, laying the basis for developing hemichannel-specific blockers.-Ponsaerts, R., De Vuyst, E., Retamal, M., D'hondt, C., Vermeire, D., Wang, N., De Smedt, H., Zimmermann, P., Himpens, B., Vereecke, J., Leybaert, L., Bultynck, G. Intramolecular loop/tail interactions are essential for connexin 43-hemichannel activity. FASEB J. 24, 4378-4395 (2010). www.fasebj.org

Key Words: intercellular communication • actomyosin contractility $\cdot$ intracellular calcium $\cdot$ purinergic signaling
INTERCELLULAR COMMUNICATION CAN OCCUR via direct and indirect signaling pathways. In vertebrates, the protein family of connexins plays an important role in both communication modes (1-4). Connexins can regulate the spreading of intracellular messengers by forming cell-to-cell coupling gap junctions (GJs) and mediate paracrine communication by the release of signaling molecules into the extracellular environment via unopposed hemichannels (5). GJs are formed by the juxtaposition at the intercellular interface of 2 hemichannels (connexons), which each consist of 6 connexin proteins. Connexins form highly conductive and permeable channel complexes, allowing the flux of hydrophilic signaling molecules smaller than $1.2 \mathrm{kDa}$, including inositol 1,4,5-trisphosphate and ATP $(2,6)$. Many of these signaling molecules provoke $\mathrm{Ca}^{2+}$ signals in neighboring cells, thereby controlling cellular function in multicellular systems (7). The activity of connexin channels, particularly hemichannels, must be tightly regulated and is characterized by brief openings in normal, healthy cells (8). However, pathological conditions may lead to more pronounced opening of hemichannels (8-13), and under ischemic conditions this may lead to a collapse of electrochemical gradients, loss of metabolites, and massive $\mathrm{Ca}^{2+}$ entry (14).

More than 20 connexin proteins have been identified in mammalian cells, characterized by distinct molecular weights. Some of these connexins appear to be reserved for specific cell types, but connexin 43 (Cx43) is widely expressed and ubiquitously present in a variety of cell types, including the cells of major organs such as heart and brain $(15,16)$. Recent studies provided important insights in the modulation of GJ channel gating. Delmar and co-workers (17-20) proposed that

\footnotetext{
${ }^{1}$ These authors contributed equally to this work.

${ }^{2}$ These authors contributed equally to this work.

${ }^{3}$ Correspondence: Laboratory of Molecular and Cellular Signaling, Department Molecular Cell Biology, K.U. Leuven, Campus Gasthuisberg $\mathrm{O} / \mathrm{N}-1$ bus 802 , Herestraat 49, BE-3000 Leuven, Belgium. E-mail: geert.bultynck@med.kuleuven.be doi: $10.1096 /$ fj.09-153007
} 
the closure of $\mathrm{Cx} 43 \mathrm{GJ}$ channels in response to acidification is mediated by a "ball-and-chain" model whereby the intracellular CT tail interacts with a receptor sequence on the CL (located between transmembrane domains 2 and 3). This ball-and-chain model was also invoked to explain chemical gating and the fast component of voltage-dependent gating $(18,19)$. These findings were supported by binding and structural approaches, leading to the identification of an intramolecular interaction between the CT tail and the L2 region (aa 119-144), in the CL $(21,22)$. Physical binding of the ball (CT) to the receptor (CL) induced a residual state with very low conductance, whereas displacement of the ball from the receptor provoked the full open state (23). Two residues in the L2 region (H126 and I130) seemed to be important for the structural integrity of this domain, which consists of $2 \alpha$-helical structures (24). In addition, besides these intramolecular interactions, the CT tail of Cx43 GJs also interacts with a plethora of proteins, including cytoskeletal-associated proteins (reviewed in ref. 25-27).

Although much effort has been invested in understanding the functional regulation of GJs, our knowledge on the regulation of hemichannels is still in its infancy. The aim of the present work was to determine whether intramolecular loop/tail interactions that are known to regulate GJs also affect hemichannel activity.

\section{MATERIALS AND METHODS}

\section{Cell culture}

Primary cultures of bovine corneal endothelial cells (BCECs) were established as described previously $(28,29)$. First- and second-passage cells were used for experiments. HeLa cells stably transfected with either the full-length Cx43 (30) or the CT-truncated mutant of $\mathrm{Cx} 43\left(\mathrm{Cx} 43^{\mathrm{M} 239}\right)$ (30) were maintained in DMEM, supplemented with $10 \%$ fetal bovine serum (Invitrogen, Merelbeke, Belgium). C6 glioma cells stably transfected with Cx43 (31) were maintained in DMEM:Ham's F12 (1:1; Invitrogen) supplemented with $10 \%$ fetal bovine serum. For all live-cell microscopy experiments, BCECs were seeded into 2-chambered glass slides at a density of 165,000 cells/chamber $\left(4.2 \mathrm{~cm}^{2}\right)$. For automated analysis using FlexStation 3 (Molecular Devices, Sunnyvale, CA, USA), BCECs were plated out at 15,000 cells/well for 96-well plates. For ATP-release measurements, HeLa and C6 cells were seeded at a density of $10^{5}$ cells/well in a 24-well plate and used on the next day for experiments (subconfluent cultures).

\section{Chemicals}

Fluo-4 AM (F14217), Fura-2 AM (F1201), Dulbecco's PBS (14190-091), Dulbecco's modified Eagle medium (11960044), L-glutamine (Glutamax, 35050-038), antibiotic-antimycotic mixture (15240-096), Earle's balanced salt solution (14155-048), and trypsin (25300-054) were obtained from Invitrogen. Fetal bovine serum (F-7524), a luciferin-luciferase bioluminescence assay kit, ATP, apyrase VI (A6410), apyrase VII (A6535), ARL-67156 (6- $N, N$-diethyl- $\beta, \gamma$-dibromomethylene-D-ATP; A265), propidium iodide (PI; 81845), thrombin (T-4648), LY (L-0259), and (-)-blebbistatin (B0560; a 1-phenyl-1,2-pyrrolidine derivative) were obtained from SigmaAldrich (Deisenhofen, Germany). The $(+)$-enantiomer of blebbistatin was obtained from Calbiochem (203392; Merck Biosciences, Darmstadt, Germany).

\section{Peptides}

All synthetic peptides ( $>90 \%$ pure) were obtained from Thermo Electron (Ulm, Germany). Table 1 shows the sequence of the different TAT-fused peptides used in this study. In all experiments, TAT peptides were used at $100 \mu \mathrm{M}$ and incubated with the cells for $30 \mathrm{~min}$ at $37^{\circ} \mathrm{C}$.

\section{SiRNA against Cx43 in BCECs}

SiRNA-duplex oligonucleotides against bovine Cx43 (gi 88319926:206-1357) were designed and screened for off-target sequences using Batch RNAi selector (32) (sense siCx 43-1: 5'GAAGGAGGAGGAACU-CAAAdTdT; sense siCx 43-2: 5'CAAUUCUUCCUGCCGCAAUdTdT). A scrambled sequence of siCx43-1 was used as negative control (sense siSCR: 5'GGUAAACG-GAACGAGAAGAdTdT). Annealed siRNA was purchased (Eurogentec, Luik, Belgium), and BCECs were transfected in Gibco Optimem (Invitrogen) with HiPerFect transfection reagent (Qiagen, Venlo, The Netherlands) following the manufacturer's protocols. After $4 \mathrm{~h}$ incubation, complete culture medium for BCECs was added. Transfection efficiency of siRNA probes was assessed by confocal microscopy using duplex siRNA, containing a fluorescence Alexa Fluor 546 label at the $3^{\prime}$ end of the sense strand. Knockdown was examined by Western blot analysis using mouse monoclonal anti-Cx43 (C8093; Sigma-Aldrich). The purinergic $\mathrm{P}_{2} \mathrm{X}_{7}$-receptor was used as a loading control using a rabbit polyclonal antibody (P8232; Sigma-Aldrich). Immunoreactive bands were quantified using ImageQuant (GE Healthcare BioScience, Uppsala, Sweden).

\section{Scrape-loading dye transfer assay}

Confluent BCECs were exposed to a PBS solution containing $\mathrm{Ca}^{2+}$ and $\mathrm{Mg}^{2+}$ supplemented with $5 \mathrm{mg} / \mathrm{ml} \mathrm{PI}$, and a needle

TABLE 1. Overview of the sequence of different TAT-fused peptides used in this study

\begin{tabular}{ll}
\hline \hline TAT peptide & \multicolumn{1}{c}{ Peptide sequence } \\
\hline TAT-Cx43CT & TAT-SRPRPDDLEI \\
TAT-Cx43CTrev & TAT-SIELDDPRPR \\
TAT-Cx43CT $\Delta \mathrm{I}$ & TAT-SRPRPDDLE \\
TAT-L2 & TAT-DGANVDMHLKQIEIKKFKYGIEEHGK \\
TAT-L2 ${ }^{\text {H126K/I130N }}$ TAT-DGANVDMKLKQNEIKKFKYGIEEHGK \\
TAT-Cx50CT & TAT-SRARSDDLTV \\
TAT-Cx50L2 & TAT-GGERAPLAADQGSVKKSSSSSKGTKK \\
\hline
\end{tabular}

YGRKKRRQRRR was used as the TAT sequence, which is responsible for cell penetration of the peptides. 
scratch was applied. After $8 \mathrm{~min}$, cells were washed with PBS and fixed with $4 \%$ paraformaldehyde solution. DIC and fluorescence images were acquired using confocal microscopy (LSM510; Carl Zeiss Meditec, Jena, Germany) with laser excitation at $543 \mathrm{~nm}$ and emission detection with an LP585 filter.

\section{Imaging of $\mathrm{Ca}^{2+}$-wave propagation}

$\mathrm{Ca}^{2+}$-wave propagation was assayed as described previously. In brief, BCECs were loaded with the $\mathrm{Ca}^{2+}$-sensitive fluorescent dye Fluo-4AM $(10 \mu \mathrm{M})$ for $30 \mathrm{~min}$ at $37^{\circ} \mathrm{C}$ on a rocking shaker. Fluo-4 loading and experiments were performed in PBS (in mM: $0.9 \mathrm{CaCl}_{2}, 0.5 \mathrm{MgCl}_{2}, 2.7 \mathrm{KCl}, 1.5 \mathrm{KH}_{2} \mathrm{PO}_{4}, 138$ $\mathrm{NaCl}, 8.1 \mathrm{Na}_{2} \mathrm{HPO}_{4}, 25$ glucose, $\mathrm{pH}$ 7.0). TAT peptides (100 $\mu \mathrm{M})$ were present in the bath solution during Fluo-4 loading. After washing the cells, $\mathrm{Ca}^{2+}$ waves were elicited by briefly touching the cell membrane with a glass micropipette coupled to a piezoelectric crystal and visualized using confocal microscopy with laser excitation at $488 \mathrm{~nm}$ and emission detection at $530 \mathrm{~nm}$. The total surface area of responsive cells (active area) was determined using imaging software (LSM Image 4.2; Zeiss). All values were obtained from at least 3 independent experiments, using 8-12 replicates/experiment. Some experiments were performed in the presence of apyrase VI $(5 \mathrm{U} / \mathrm{ml})+$ apyrase VII $(5 \mathrm{U} / \mathrm{ml})$ or in the presence of ARL-67156 $(100 \mu \mathrm{M})$, indicated in the text as apyrase and ARL, respectively.

\section{Measurement of $\left[\mathrm{Ca}^{2+}\right]_{\mathrm{i}}$}

BCECs were grown to confluence over 2-3 d in 96-well plates (Cytowell 96F Fluocarbon Black, 146520; Nunc Thermo Fisher Scientific, Rochester, NY, USA) and loaded with $1.25 \mu \mathrm{M}$ Fura-2 AM in PBS (in mM: $0.9 \mathrm{CaCl}_{2}, 0.5$ $\mathrm{MgCl}_{2}, 2.7 \mathrm{KCl}, 1.5 \mathrm{KH}_{2} \mathrm{PO}_{4}, 138 \mathrm{NaCl}, 8.1 \mathrm{Na}_{2} \mathrm{HPO}_{4}, 25$ glucose, $\mathrm{pH} 7.0$ ) for $30 \mathrm{~min}$ at room temperature (RT). ATP-induced $\left[\mathrm{Ca}^{2+}\right]_{\mathrm{i}}$ rises in BCECs were measured ratiometrically (excitation at $340 \mathrm{~nm} / 380 \mathrm{~nm}$, emission detection at $510 \mathrm{~nm}$ ) in flex mode by optical bottom reading (FlexStation 3). $R_{\max }-R_{0}$ values of F340/F380 at different [ATP] were fitted to a sigmoidal curve using Origin 7.0 (OriginLab Corp., Northampton, MA, USA).

\section{Measurement of ATP release}

BCECs, grown to confluence over 2-3 d in 96-well plates (Microwell 96F White, 136101; Nunc), were incubated with PBS (in mM: $0.9 \mathrm{CaCl}_{2}, 0.5 \mathrm{MgCl}_{2}, 2.7 \mathrm{KCl}, 1.5 \mathrm{KH}_{2} \mathrm{PO}_{4}, 138$ $\mathrm{NaCl}, 8.1 \mathrm{Na}_{2} \mathrm{HPO}_{4}, 25$ glucose, $\mathrm{pH} 7.0$ ) at $37^{\circ} \mathrm{C}$ for $30 \mathrm{~min}$. ATP release was measured by luciferin-luciferase bioluminescence in kinetic mode by top-reading (integration time 1000 $\mathrm{ms}$ ) at $\mathrm{pH} 7.4$ (HBSS buffer with $25 \mathrm{mM}$ HEPES) in the presence of EGTA (3.2 mM final). Next, cells were permeabilized with saponin $(0.05 \%$ final $)$, and the total ATP amount was measured for each well. The photons emitted in response to EGTA were normalized to the values obtained after saponin treatment.

ATP release from HeLa and C6 cells was triggered by applying $\mathrm{A} 23187(0.1,2$, and $10 \mu \mathrm{M})$ and determined with a luciferin/luciferase assay kit as described previously $(33,34)$. Cellular ATP release was accumulated over the period of trigger exposure $(5 \mathrm{~min})$. Baseline measurements were performed on separate cultures using standard HBSS-HEPES. All values were calculated as fold induction compared to the values obtained from baseline measurements. All individual data points were obtained from at least 6 independent measurements.

\section{Measurement of Lucifer Yellow (LY) uptake}

After treating BCECs with TAT peptides, cells were incubated in $\mathrm{Ca}^{2+}$-free LY solution (PBS containing 2 mM EDTA and $2.5 \%$ LY) for $5 \mathrm{~min}$. Thrombin treatment preceded the exposure to LY solution by $1 \mathrm{~min}$. Excess of extracellular LY was washed away with $\mathrm{Ca}^{2+}$-rich PBS. Dye uptake was visualized using confocal microscopy (excitation at $488 \mathrm{~nm}$, emission detection at 530 nm) $(28,35-37)$.

\section{Visualization of TAT-Cx43CT peptides by immunocytochemistry}

After treating BCECs with TAT peptides, cells were fixed with $4 \%$ paraformaldehyde $\mathrm{PBS}$ solution for $20 \mathrm{~min}$ at $37^{\circ} \mathrm{C}$ and subsequently permeabilized with a $0.05 \%$ saponin PBS solution. After blocking with $10 \%$ goat serum and 3\% BSA, samples were incubated with primary monoclonal anti-TAT antibody (no. 2547, Cell Signaling Technology, Beverly, MA, USA) for $3 \mathrm{~h}$ at RT in the presence of $1 \%$ glycine. After washing, samples were incubated with the secondary antibody (goat anti-mouse IgG-FITC, F-2012; Sigma-Aldrich) for $2 \mathrm{~h}$ at RT. All incubation and washing steps were done in the presence of $0.01 \%$ saponin. To check for nonspecificity of the primary antibody, incubation with this antibody was omitted in the negative control sample. Finally, cells were costained for F-actin by incubation with Alexa-546 conjugated to phalloidin (A22283; Invitrogen), as described previously (37). Immunofluorescence images were acquired by confocal microscopy (LSM510) with a $\times 63$ oil-immersion objective (1.4 NA).

\section{Immunoprecipitation and Western blot analysis}

Cells were lyzed in lysis buffer containing $1 \%$ Nonidet P-40, $40 \mathrm{mM}$ Tris, $150 \mathrm{mM} \mathrm{NaCl}, 2 \mathrm{mM}$ EDTA, $0.25 \%$ deoxycholate, phosphatase inhibitors cocktail $1+2$ (P2850, P5726; SigmaAldrich), and protease inhibitors (11873580001; Roche Applied Science, Mannheim, Germany). Cx43 was immunoprecipitated from the detergent-soluble lysate fraction with a rabbit polyclonal antibody directed against the $\mathrm{N}$-terminal region of Cx43 (AP1541b; Abgent, San Diego, CA, USA), using protein A/G plus agarose-beads (sc-2003; Santa Cruz Biotechnology, Santa Cruz, CA, USA). Samples were subjected to SDS-PAGE and Western blotting. Immunodetection was performed as described previously (37): a mouse monoclonal IgM antibody directed against the CT of Cx43 (C8093; Sigma-Aldrich) was used as primary antibody to detect immunoprecipitated $\mathrm{Cx} 43$. ZO-1 was detected using a mouse monoclonal IgG1 antibody (33-9100; Invitrogen). After incubation with the alkaline phosphatase-conjugated secondary antibody and dephosphorylation of enhanced chemifluorescence substrate (GE Healthcare), the immunoreactive bands were visualized and quantified using a Storm 840 FluorImager equipped with ImageQuant 5.2 software (Molecular Dynamics, Sunnyvale, CA, USA). Cx50 was detected by using anti-N-terminal GJA8 antibody (AP1548a; Abgent) and visualized using HRP-labeled secondary antibody and ECL detection.

\section{Purification of PDZ-2 domain of human ZO-1}

The PDZ-2 domain of ZO-1 was cloned in a pGEX-5X vector (GE Healthcare). The PDZ-2 domain was expressed in E. coli and purified as described previously (38). 


\section{Surface plasmon resonance (SPR) using biotin-Cx43CT peptides}

All SPR experiments were performed using Biacore 2000. Equal amounts (resonance units) of $>95 \%$ pure biotinylated peptides were immobilized on each flow cell of a streptavidincoated sensor chip (BR-1000-32; Biacore, Uppsala, Sweden) using HEPES buffer (in mM: 10 HEPES, 1 EDTA, $100 \mathrm{NaCl}$ ) with $0.005 \%$ polysorbate-20 (Tween-20) at $\mathrm{pH} 7.4$. Measurements with analyte were done in HEPES buffer at a flow rate of $30 \mu \mathrm{l} / \mathrm{min}$. Binding of analyte was verified at different concentrations, in random order (injection volume $120 \mu \mathrm{l}$ ). Bound peptide was removed by injection of $10 \mu \mathrm{l}$ regeneration buffer $(50 \mathrm{mM} \mathrm{NaOH}, 1 \mathrm{M} \mathrm{NaCl})$ at $10 \mu \mathrm{l} / \mathrm{min}$. Measurements with TAT-L2 were done in analytically prepared buffers containing $500 \mathrm{nM}$ free $\left[\mathrm{Ca}^{2+}\right]$, calculated via CaBuf (G. Droogmans; ftp://ftp.cc.kuleuven.ac.be/pub/ droogmans/cabuf.zip). Background signals obtained from the reference flow cell, containing the reversed biotinylated peptide, were subtracted to generate response curves. In each sensorgram, the first and the second arrows illustrate the beginning of association and dissociation, respectively.

\section{cRNA preparation and injection into Xenopus laevis oocytes}

Cx43 cDNA was obtained from Dr. Guillermo Altenberg (Texas Tech University Health Sciences Center, College Station, TX, USA) as plasmid pOocyte-Cx43. The cDNA was first linearized with SaII, and then cRNA was obtained by using T7-directed capped cRNA synthesis kit (mMessage Machine; Ambion, Austin, TX, USA). The cRNA was precipitated overnight with $\mathrm{LiCl}$ at $-80^{\circ} \mathrm{C}$. Oocytes were obtained as described previously (39). Briefly, extracted oocytes were incubated in OR2 (in mM: $82.5 \mathrm{NaCl}, 2 \mathrm{KCl}, 1 \mathrm{MgCl}_{2}$, and 5 HEPES, $\mathrm{pH}$ 7.4) solution plus $0.5 \mathrm{mg} / \mathrm{ml}$ of collagenase for $80 \mathrm{~min}$ at RT under constant rotation. Then, oocytes were washed 3 times (15 min each) with OR2 solution and then twice (15 min each) with Barth's solution (in mM: $88 \mathrm{NaCl}, 1$ $\mathrm{KCl}, 1.8 \mathrm{CaCl}_{2}, 1.0 \mathrm{MgCl}_{2}, 10$ HEPES, $\mathrm{pH}$ 7.4, supplemented with $0.1 \mathrm{mg} / \mathrm{ml}$ gentamicin and $20 \mathrm{U} / \mathrm{ml}$ of penicillin and streptomycin). Finally, oocytes were kept in Barth's solution, and the medium was changed each 1-2 d. Oocytes were injected with antisense Cx38 (12.5 ng) oligonucleotide and cRNA coding for $\mathrm{Cx} 43$ (50 ng). All experiments were performed after $48 \mathrm{~h}$ post-cRNA injection.

\section{Electrophysiological recordings and analysis}

Hemichannel currents were measured as described previously (39). Briefly, oocytes were bathed at RT with ND96 solution (in mM: $96 \mathrm{NaCl}, 2 \mathrm{KCl}, 1.8 \mathrm{CaCl}_{2}, 1.0 \mathrm{MgCl}_{2}$, and 5 HEPES, $\mathrm{pH}$ 7.4). Two-electrode whole-cell voltage-clamp recordings and analysis were performed with pClamp 10/Digidata 1440A A/D Board (Molecular Devices, Foster City, CA, USA). Hemichannel currents were measured as 15-s square pulses, ranging from -60 to $+60 \mathrm{mV}$ in $10-\mathrm{mV}$ steps, with a following 10-s interval between pulses at holding potential equal to $-60 \mathrm{mV}$. Current-voltage $(I-V)$ relationships were calculated from the current values at the end of each depolarizing pulse.

\section{Statistical analysis}

Results are expressed as means $\pm \mathrm{SE}$, and $n$ refers to the number of independent experiments. For statistical analyses, each treatment was compared to its respective control, and significance was determined using a 1-way ANOVA or paired
Student's $t$ test, as appropriate. Differences were considered significant at $P<0.05$.

\section{RESULTS}

\section{Intercellular $\mathrm{Ca}^{2+}$-wave propagation in BCECs is mainly driven by $\mathrm{Cx} 43$ hemichannel-mediated ATP release}

We examined intercellular communication in BCECs by measuring intercellular $\mathrm{Ca}^{2+}$-wave propagation and ATP release. $\mathrm{Ca}^{2+}$-wave propagation was triggered by applying a mechanical stimulus (MS) to a single cell of the monolayer, and the total surface area of the responding cells (active area) was quantified. We previously demonstrated that intercellular communication in monolayers of BCECs relies in large part on a paracrine pathway that involves ATP release via hemichannels $(28,29)$. Figure $1 \boldsymbol{A}$ shows the active area determined in untreated BCECs and cells treated either with ARL, an inhibitor of ectoATPases (40), or with apyrases, enzymes catalyzing the hydrolysis of ATP. The ARL treatment increases ATP-dependent intercellular communication by inhibiting ATP hydrolysis, whereas the apyrase treatment inhibits ATP-mediated intercellular communication, rendering cells largely dependent on GJ coupling for their intercellular communication. Figure $1 A$ shows that ARL treatment increased the active area 3.4-fold, whereas apyrase treatment reduced the active area to $\sim 30 \%$ of the original value. These results indicate that mechanical stimulation-induced $\mathrm{Ca}^{2+}$-wave propagation largely depends on hemichannel-mediated ATP release.

To clarify the cellular role of Cx43 hemichannels in our cell system, we investigated intercellular communication after Cx43 knockdown. Using a fluorescently labeled probe, we show that the majority of cells in confluent BCEC monolayers contained the siRNA probes (Supplemental Fig. 1). Both siCx43 probes provoked a knockdown of $\mathrm{Cx} 43$ at the protein level of $\sim 90 \%$ relative to $\mathrm{P}_{2} \mathrm{X}_{7}$ levels, which were used as a loading control (Fig. 1B). Furthermore, both siCx43 probes provoked a pronounced decrease in the spreading of PI in scrape-loaded BCECs (Fig. 1C), indicating that BCECs contain functional Cx43 GJs.

Next, we investigated the effect of siCx43 on intercellular communication by measuring intercellular $\mathrm{Ca}^{2+}$-wave propagation (Fig. $1 D, E, G$ ) and ATP release $($ Fig. $1 H$ ). Both siCx43 probes potently decreased the active area compared to control conditions (Fig. $1 E$ and Supplemental Fig. 2A), whereas the amplitude of the $\left[\mathrm{Ca}^{2+}\right]_{\mathrm{i}}$ rise in the MS cell was not significantly affected (Table 2). Furthermore, siRNA treatment did not significantly affect the ATP-induced $\left[\mathrm{Ca}^{2+}\right]_{\mathrm{i}}$ increase (Fig. $1 F)$. The active area was also determined in the presence of ARL and apyrases (Fig. $1 G$ ). Treatment of the cells with siCx43 probes resulted in a very marked, significant reduction in the active area in the presence 
A
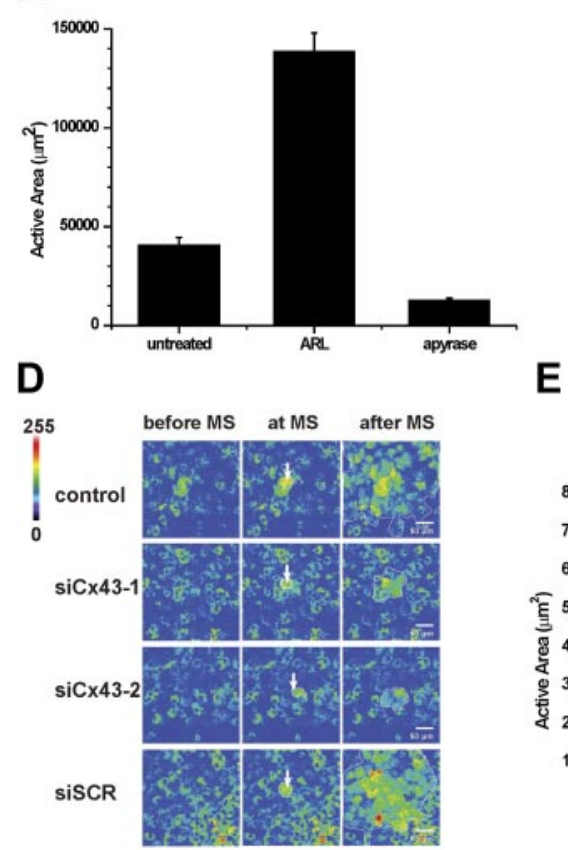

G

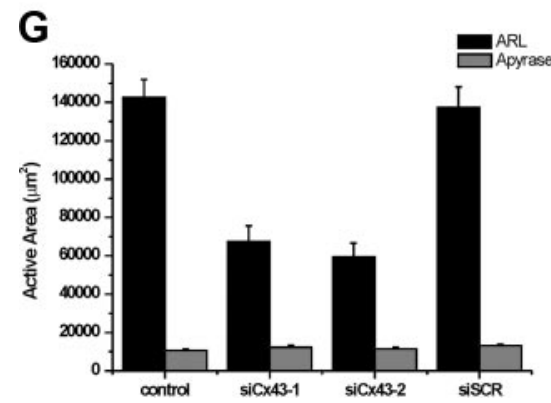

B
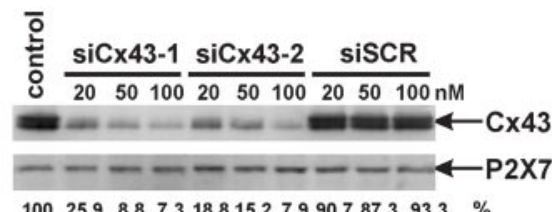

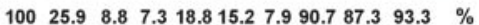

\section{C}

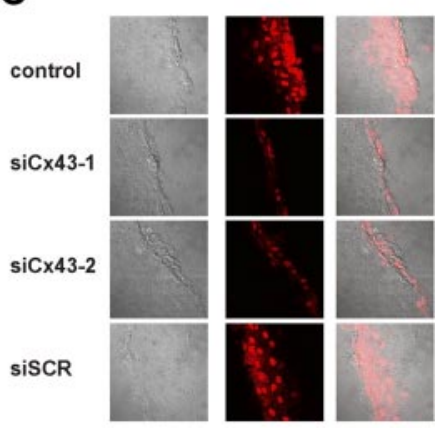

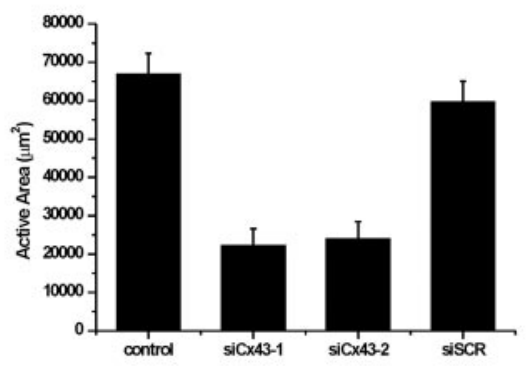

H

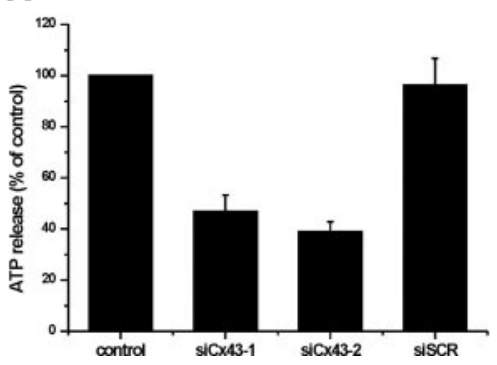

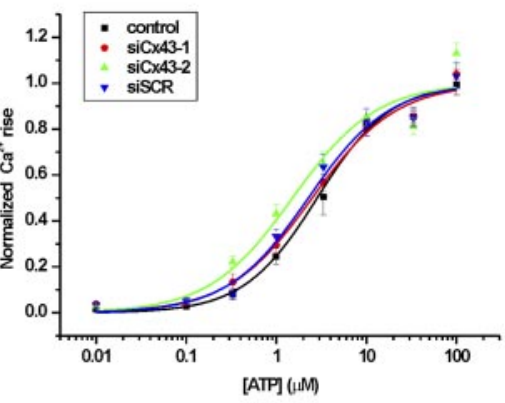

Figure 1. Endogenous Cx43 mediates intercellular communication and hemichannel-mediated ATP release in BCECs. A) Active area of the intercellular $\mathrm{Ca}^{2+}$-wave propagation in BCECs in control conditions, in the presence of ARL and in the presence of apyrase. B) Immunoblot of $\mathrm{Cx} 43$ and $\mathrm{P}_{2} \mathrm{X}_{7}$ in lysates prepared from BCECs treated with different amounts (20, 50, and $100 \mathrm{nM}$ ) of siRNA duplexes (2 independent siRNA probes against $\mathrm{Cx} 43$ : siCx43-1 and siCx43-2; a scrambled siRNA probe: siSCR). Controls are always treated with transfection reagent only. Numbers in bottom row indicate Cx43-protein levels relative to the P2X $\mathrm{X}_{7}$-protein levels. C) Scrape loading of BCECs with propidium iodide (red) in the presence of different siRNA probes. $D, E$ ) MS-induced intercellular $\mathrm{Ca}^{2+}$-wave propagation in BCECs treated with siRNA duplexes. $D$ ) Representative images before MS (left), at the time of MS (middle), and at the time when the $\mathrm{Ca}^{2+}$-wave propagation reaches its maximal spreading (active area; right). E) Quantitative analysis of the active area of the intercellular $\mathrm{Ca}^{2+}$-wave propagation $\left.(n=4) . F\right)$ Normalized ATP-induced $\left[\mathrm{Ca}^{2+}\right]_{\mathrm{i}}$ rise in BCECs treated with siRNA duplexes. G) Quantitative analysis of the active area of the intercellular $\mathrm{Ca}^{2+}$-wave propagation in the presence of either ARL or apyrase in BCECs treated with siRNA duplexes. $H$ ) $\mathrm{Ca}^{2+}$-free solution-induced ATP release from BCECs treated with siRNA duplexes $(n=4)$.

of ARL, but had no significant effect in the presence of apyrases, demonstrating that $\mathrm{Ca}^{2+}$-wave propagation in BCECs largely depends on ATP release via Cx43 hemichannels.

Next, we assessed the effect of Cx43 knockdown on hemichannel-mediated ATP release triggered by expos-

TABLE 2. Relative Fluo-4 fluorescence increase $\left(\Delta F / F_{0}\right)$ in the MS cell

\begin{tabular}{lc}
\hline \hline Treatment & Relative fluorescence units \\
\hline Control & $0.815 \pm 0.126$ \\
siCx43-1 & $0.742 \pm 0.250$ \\
siCx43-2 & $0.673 \pm 0.188$ \\
siSCR & $0.872 \pm 0.152$ \\
\hline
\end{tabular}

Values are expressed as means \pm SE from 3 independent experiments. Control was treated with transfection reagent. Values do not differ significantly from control $(P>0.1$; paired $t$ test $)$. ing BCECs to a $\mathrm{Ca}^{2+}$-free solution containing EGTA, a potent trigger for connexin-hemichannel opening (4144). Cells treated with siCx43-1 or siCx43-2 displayed a $55 \%$ decrease in the amount of EGTA-induced ATP release (Fig. $1 H$ ).

Taken together, these results indicate that $\mathrm{Ca}^{2+}$-wave propagation in BCECs is in large part mediated by signaling via $\mathrm{Cx} 43$ hemichannels, despite the presence of functional Cx43 GJs. Therefore, Cx43 is a major player in ATP-mediated paracrine communication in BCECs.

A peptide corresponding to the last $10 \mathrm{CT}$ aa of Cx43 (TAT-Cx43CT) prevents thrombin-induced inhibition of intercellular $\mathrm{Ca}^{2+}$ waves and $\mathrm{LY}$ uptake

Because Cx43 plays an important role in ATP-dependent paracrine signaling in BCECs (Fig. 1) and because 
thrombin inhibits this paracrine component (35) by increasing actomyosin contractility (37), we investigated the mechanism by which the contractile system regulates Cx43-hemichannel activity (see Fig. 10 for the model).

For Cx43 GJ channels, the 220-kDa peripheral membrane protein ZO-1 has been shown to link the actomyosin cytoskeleton with the CT tail of $\mathrm{Cx} 43$ and regulate Cx43-channel activity (45-47). The 4 aa located at the CT end (DLEI) of Cx43 act as PDZ-binding domain responsible for the interaction with the second PDZ domain of ZO-1 (48-50). Note that antennapediacoupled peptide corresponding to the last 9 aa of $\mathrm{Cx} 43$ was able to inhibit the endogenous interaction between PDZ-2 of ZO-1 and Cx43 GJs (46).

In this study we investigated whether the CT part of Cx43 is also involved in the inhibitory effect of thrombin on intercellular communication. Therefore, we developed cell-permeable peptides corresponding to the last 10 aa of Cx43 (TAT-Cx43CT) and its reverse sequence (TAT-Cx43CTrev). Covalent coupling of peptides to the TAT sequence is a well-documented approach for cellular delivery of peptides (51).

First, we show that both peptides accumulated in the intracellular environment of BCECs (Fig. 2A). Second, we examined the effect of these peptides on the thrombin-induced inhibition of $\mathrm{Ca}^{2+}$-wave propagation and LY uptake. The $\mathrm{Ca}^{2+}$-wave propagation experiments were performed in the absence and presence of ARL. As previously shown, thrombin caused a marked reduction in the active area in BCECs (Fig. 2B, top panel) $(35,37)$. Interestingly, preincubation with TATCx43CT largely prevented the inhibition of the $\mathrm{Ca}^{2+}$. wave propagation by thrombin in the absence as well as in the presence of ARL, whereas TAT-Cx43CTrev did not have any effect. Furthermore, these peptides did not affect the $\mathrm{Ca}^{2+}$-wave propagation in the absence of thrombin. TAT-Cx43CT also prevented the inhibitory effect of thrombin on LY uptake in response to $\mathrm{Ca}^{2+}$. free solution (Fig. 2C).

Third, we examined the contribution of Cx50 in our cell system for the following reasons: Cx43 and Cx50 are both GJA-type connexins; the CT region of $\mathrm{Cx} 43$ and Cx50 display homology; and we have found $\mathrm{Cx} 50$ at the mRNA level in BCECs (52). However, the effects of TAT-Cx43CT are unlikely to be due to effects on Cx50: Cx50 protein could not be detected by Western blot analysis using an anti-Cx50 antibody in BCECs (Supplemental Fig. 3A), and TAT-Cx50CT (last 10 aa of Cx50) did not affect the thrombin-induced inhibition of the $\mathrm{Ca}^{2+}$-wave propagation (Supplemental Fig. 3B). Because TAT-Cx50CT resembles TAT-Cx43CT except for 2 proline residues, the latter result also suggests that
A

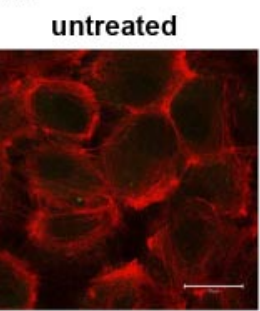

TAT-CX43CT

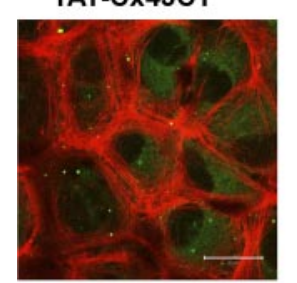

TAT-CX43CTrev

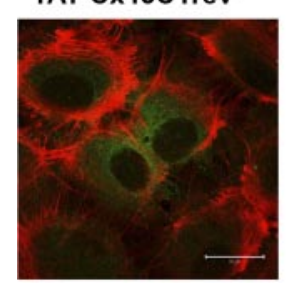

B
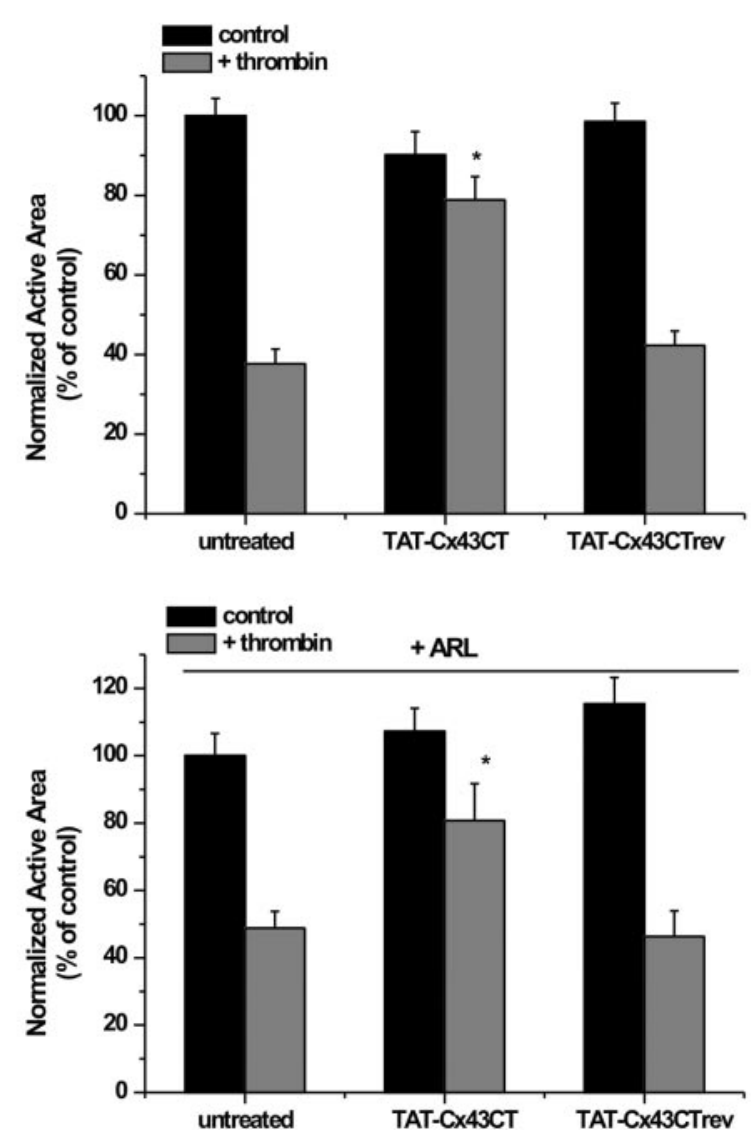

C

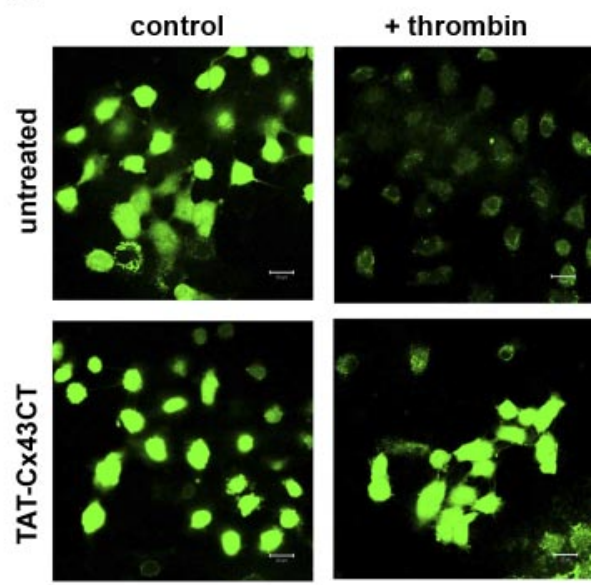

Figure 2. TAT-Cx43CT peptides prevent thrombin-induced inhibition of hemichannel opening in BCECs. Cells were pretreated with $100 \mu \mathrm{M}$ of TAT-Cx43CT or TAT-Cx43CTrev before adding either PBS or thrombin. A) Immunofluorescence of TAT peptides in BCECs using monoclonal anti-TAT (green). F-actin is stained with phalloidin-AlexaFluor546 (red). B) Thrombin-induced inhibition of intercellular $\mathrm{Ca}^{2+}$-wave propagation in BCECs in response to MS pretreated with different TAT peptides in the absence (top panel) and presence (bottom panel) of ARL. Quantification of the normalized active area is shown $(n=4) . * P<0.05$ vs. control or TAT-Cx43CTrev-treated cells, both preincubated with thrombin. C) Thrombin-induced inhibition of LY uptake induced by $\mathrm{Ca}^{2+}$-free solution in BCECs pretreated with TAT-Cx43CT. Scale bars $=20 \mu \mathrm{m}$. 
the proline residues are important for the effects of TAT-Cx43CT.

\section{Thrombin-induced inhibition of intercellular $\mathrm{Ca}^{2+}$ waves is not mediated through $\mathrm{ZO}-1$}

Because TAT-Cx43CT prevents thrombin-induced inhibition of Cx43-hemichannel activity, we investigated whether this effect of TAT-Cx43CT was due to disturbing the interaction of ZO-1 with the CT tail of Cx43. Therefore, we developed a TAT-Cx43CT $\Delta$ I peptide, lacking the last isoleucine residue that is essential for binding of $\mathrm{Cx} 43$ with the PDZ-2 domain of ZO-1 $\left(\mathrm{PDZ2}^{\mathrm{ZO}-1}\right)(48,53)$.

First, we confirmed whether the last isoleucine of the Cx43CT peptide is essential for interaction with PDZ2 ${ }^{\mathrm{ZO}-1}$. Therefore, the binding of purified PDZ2 ${ }^{\mathrm{ZO}-1}$ to immobilized biotin-Cx43CT was examined using SPR (Fig. 3A). As shown previously (54), addition of PDZ2 ${ }^{\mathrm{ZO}-1}$ caused concentrationdependent changes in the angle of resonance, indicating a specific interaction between biotin-Cx43CT and PDZ2 ${ }^{\mathrm{ZO}-1}$. Excess Cx43CT largely prevented the binding of PDZ2 ${ }^{\mathrm{ZO}-1}$ to the immobilized biotin-Cx43CT, whereas Cx43CT $\Delta \mathrm{I}$ did not. These results confirm that the last isoleucine residue of $\mathrm{Cx} 43$ was essential for the interaction of $\mathrm{Cx} 43$ with the $\mathrm{PDZ2}^{\mathrm{ZO}-1}$, enabling us to investigate the possible involvement of ZO-1 in thrombin-induced inhibition of hemichannels in BCECs.

Second, we investigated the effects of TAT-Cx43CT $\Delta \mathrm{I}$ on the thrombin-induced inhibition of MS-induced $\mathrm{Ca}^{2+}$-wave propagation. Strikingly, TAT-Cx43CT $\Delta$ I (like TAT-Cx43CT) completely prevented the inhibition of intercellular $\mathrm{Ca}^{2+}$ wave propagation by thrombin (Fig. 3B), indicating that ZO-1 was not involved in this process.

Third, ZO-1 did not specifically coimmunoprecipitate with Cx43 solubilized from BCEC lysates that were either untreated or treated with thrombin (Fig. 3C). Taken together, these data provide evidence that ZO-1 is not involved in the effects of TAT-Cx43CT on thrombin-induced inhibition of $\mathrm{Cx} 43$ hemichannel-mediated intercellular communication.

\section{TAT-L2 inhibits Cx43-hemichannel responses}

Besides the PDZ-2-binding motif, TAT-Cx43CT contains a stretch of aa previously shown to interact with the CL of Cx43 (17, 22-24, 55), but it is not known whether the residues present in TAT-Cx43CT are sufficient for binding CL. We investigated whether such loop/tail interaction exists in Cx43 hemichannels and whether TAT-Cx43CT could interfere with it. Therefore, we developed a cell-permeable peptide (TAT-L2) that corresponds to the L2 region. We also developed a modified TAT-L2, in which 2 aa essential for binding of L2 to the CT tail of Cx43 were mutated (TAT-L2 ${ }^{\mathrm{H} 126 \mathrm{~K} / \mathrm{I130N}}$ ) (23).

Strikingly, TAT-L2, but not TAT-L2 ${ }^{\mathrm{H} 126 \mathrm{~K} / \mathrm{I} 130 \mathrm{~N}}$, provoked a potent decrease in the active area of $\mathrm{Ca}^{2+}$-wave propagation on MS (Fig. $4 A$ ). These observations were confirmed in the presence of ARL (Fig. $4 B$ ). Both results point to a strong inhibition of hemichannel responses by TAT-L2. Furthermore, the inhibition of the active area by TAT-L2 was completely abolished when ATP-mediated paracrine intercellular communication was inhibited by apyrases, and intercellular communication solely relied on GJs (Fig. 4C). The latter experiment excludes the possibility that the inhibitory effects of TAT-L2 on $\mathrm{Ca}^{2+}$ wave propagation were due to inhibition of $\mathrm{Cx} 43 \mathrm{GJ}$ channels. Therefore, these data indicate that the effect of TAT-L2 on intercellular communication is mainly due to inhibition of hemichannel-mediated ATP release, thereby resembling the effects of thrombin. Because TAT-Cx50L2 (corresponding L2 region from Cx50) did not affect the active area of the
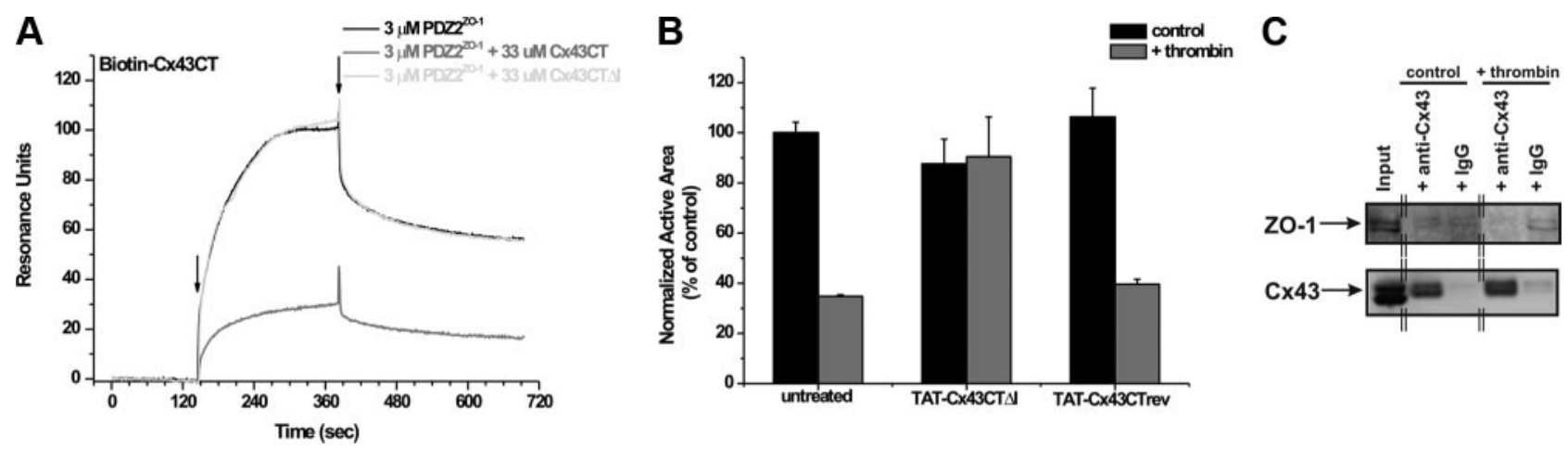

Figure 3. TAT-Cx43CT-mediated suppression of thrombin-induced inhibition of hemichannel opening in BCECs does not involve ZO-1. A) Sensorgrams illustrating the binding of the PDZ-2 domain of ZO-1 (3.3 $\mu \mathrm{M})$ to biotin-Cx43CT immobilized to a streptavidin-coated sensor chip. Untagged Cx43CT (red) or Cx43CT $\Delta \mathrm{I}$ (green) peptides were preincubated in excess $(33 \mu \mathrm{M}$ ) with PDZ-2 $(3.3 \mu \mathrm{M})$ to compete for binding of PDZ-2 to the immobilized biotin-Cx43CT. A representative experiment is shown $(n=3) . B)$ Thrombin-induced inhibition of intercellular $\mathrm{Ca}^{2+}$-wave propagation in BCECs pretreated with TAT-Cx43CT $\Delta \mathrm{I}$ in response to MS. Quantification of the normalized active area is shown ( $n=3)$. C) Immunoblots of ZO-1 and Cx43 of samples obtained after immunoprecipitation of Cx43 from lysates prepared from PBS- and thrombin-treated BCECs. The double lines indicate that the lanes were taken from another part of the same gel. The lowest band in the lysate of the Cx43 blot is GAPDH, which was stained to monitor the washing conditions of immunoprecipitated complexes. 
A

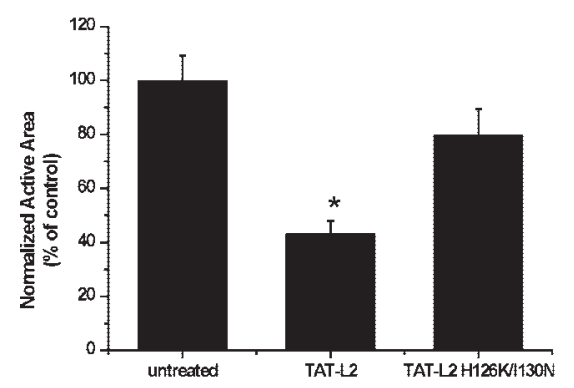

B

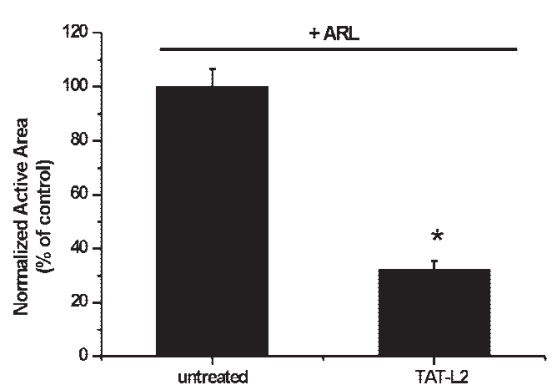

C

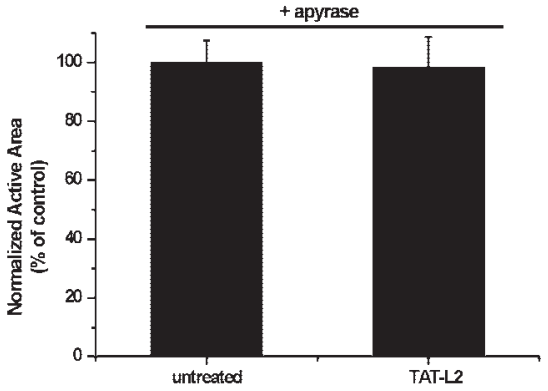

Figure 4. TAT-L2 peptide inhibits hemichannel opening in BCECs. A) BCECs were treated with either TAT-L2 or TATL2 ${ }^{\mathrm{H} 126 \mathrm{~K} / \mathrm{I} 130 \mathrm{~N}}$, and the active area of the MS-induced $\mathrm{Ca}^{2+}$-wave propagation was quantified $(n=3)$. $\left.B\right)$ Similar experiment as in panel $A$, but in the presence of ARL. C) Similar experiment as in panel $B$, but in the presence of apyrase. $* P<0.05 v s$. untreated cells or TAT-L2 ${ }^{\mathrm{H} 126 \mathrm{~K} / \mathrm{I} 130 \mathrm{~N}}$-treated cells.

$\mathrm{Ca}^{2+}$-wave propagation on MS, Cx50 seemed not to be involved (Supplemental Fig. 3C).

To elaborate on the inhibitory effect of TAT-L2 on the Cx43-hemichannel opening, we investigated ATP release from Cx43-expressing HeLa cells in response to other triggers. On the one hand, we applied $2 \mu \mathrm{M}$ of the $\mathrm{Ca}^{2+}$ ionophore A23187, elevating $\left[\mathrm{Ca}^{2+}\right]_{\mathrm{i}}$ to the $500 \mathrm{nM}$ range (Fig. 5A) and provoking $\mathrm{Cx} 43$ hemichannel-mediated ATP release in this cell system (Fig. 5B, C) $(34,56)$. On the other hand, we applied a $\mathrm{Ca}^{2+}$-free solution to open hemichannels (Fig. 5D). Strikingly, in both trigger conditions, TAT-L2 potently inhibited ATP release from these cells. In contrast, the mutant version of TAT-L2 (TATL2 $\left.{ }^{\mathrm{H} 126 \mathrm{~K} / \mathrm{I} 130 \mathrm{~N}}\right)$ was much less efficient than TAT-L2 in inhibiting Cx43-hemichannel responses (Fig. 5B), indicating that the inhibition of Cx43-hemichannel responses by
TAT-L2 involves the CT tail-binding properties of the L2 region.

Because L2 can bind to the CT tail of Cx43, we investigated whether the inhibitory effects of TAT-L2 were influenced by the presence of TAT-Cx43CT (Fig. $5 C, D)$. Therefore, we coincubated TAT-L2 with either TAT-Cx43CT or TAT-Cx43CTrev. These experiments revealed that TAT-Cx43CT, but not TAT-Cx43CTrev, was able to overcome the inhibition of $\mathrm{Cx} 43$ hemichannel-mediated ATP release by TAT-L2.

These data indicate that TAT-L2 inhibits Cx43 hemichannels by acting on the last 10 aa of $\mathrm{Cx} 43$, thereby interfering with intramolecular loop/tail interactions. Furthermore, TAT-Cx43CT neutralizes the inhibitory action of TAT-L2 on Cx43 hemichannels.
A

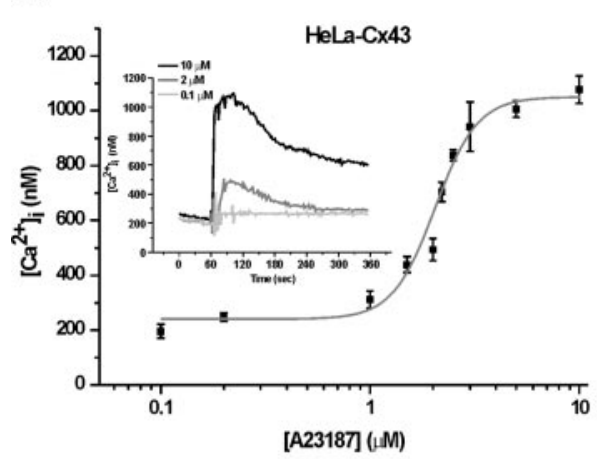

C

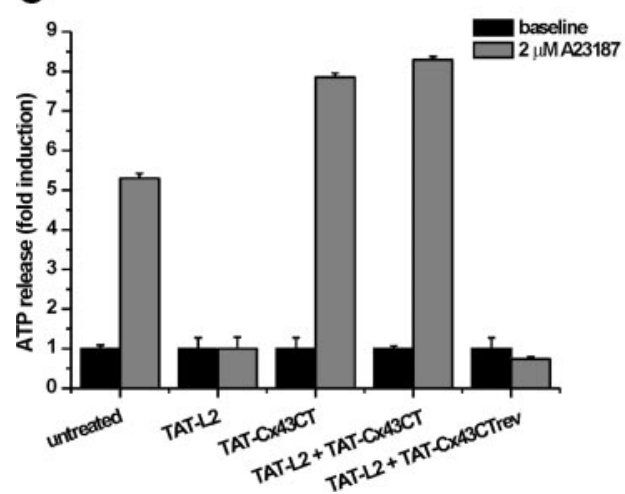

B

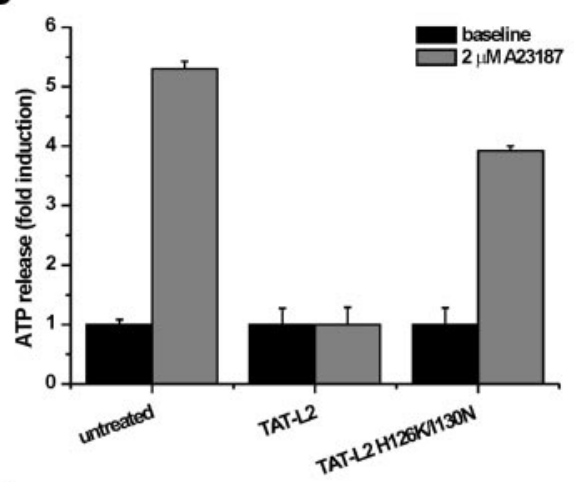

D

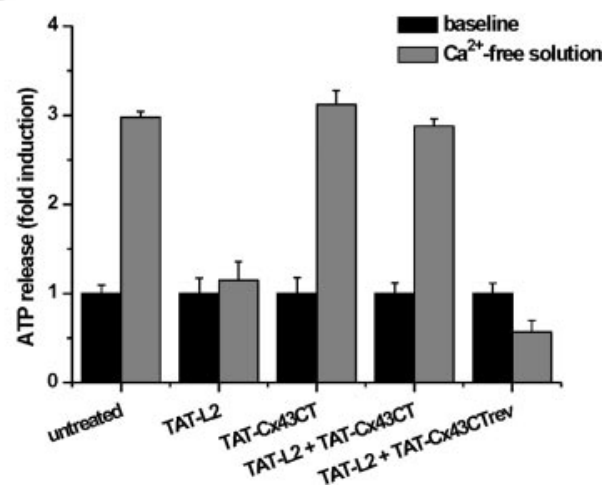

Figure 5. TAT-L2 peptide inhibits hemichannel opening in HeLa cells ectopically expressing $\mathrm{Cx} 43$. A) Dose-response curve showing the amplitude of $\left[\mathrm{Ca}^{2+}\right]_{\mathrm{i}}$ transients as a function of different [A23187], obtained from at least 3 independent experiments. The inset shows $\left[\mathrm{Ca}^{2+}\right]_{i}$ transients monitored in response to $0.1,2$, and $10 \mu \mathrm{M} \mathrm{A23187.} \mathrm{B)}$ ATP release from $\mathrm{Cx} 43$-expressing HeLa cells in response to $2 \mu \mathrm{M}$ A23187. Cells were treated for 30 min with either TAT-L2 or TAT$\mathrm{L} 2^{\mathrm{H} 126 \mathrm{~K} / \mathrm{I} 130 \mathrm{~N}}$. $C, \quad$ ) ) Cx43-expressing HeLa cells were treated with either TAT-Cx43CT, TATL2, TAT-Cx43CT + TAT-L2, or TAT-Cx43CTrev + TAT-L2. Data show ATP release as fold induction of baseline values $(n=10)$ from Cx43-expressing HeLa cells in response to $2 \mu \mathrm{M}$ A23187 (C) or $\mathrm{Ca}^{2+}$-free solution containing the $\mathrm{Ca}^{2+}$ buffer EGTA $(D)$. 


\section{Cx43CT interacts with the L2 region of $\mathrm{Cx} 43$}

Because inhibition of Cx43-hemichannel activity by TAT-L2 is alleviated by TAT-Cx43CT and because we propose that these peptides affect the loop/tail gating of $\mathrm{Cx} 43$ hemichannels, we investigated in an independent way whether Cx43CT interacts with the L2 region. Using SPR, we examined the binding of L2 to immobilized biotin-Cx43CT. Biotin-Cx43CTrev was used as a control. Figure $\mathbf{6 A}$ illustrates sensorgrams of different concentrations of the TAT-L2 peptide. The SPR measurements demonstrated a clear concentration-dependent change in resonance units on addition of TAT-L2, indicating a specific interaction between biotin-Cx43CT and TAT-L2.

Furthermore, the binding of TAT-L2 to biotinCx43CT was promoted by decreasing the $\mathrm{pH}$ from 6.8 to 5.8 (Fig. $6 B$ ). Decreasing the $\mathrm{pH}$ favors the $\alpha$-helical structure of the L2 sequence and enhances binding of the tail to the loop (22), suggesting that the structural properties of the L2 region are important for its binding to Cx43CT.

These data indicate that the last 10 aa of $\mathrm{Cx} 43$ are sufficient to interact with the L2 region of Cx43. Addition of cell-permeable peptides corresponding to these regions may therefore disturb endogenous loop/ tail interactions of $\mathrm{Cx} 43$ hemichannels and affect the regulation of $\mathrm{Cx} 43$.

(-)-Blebbistatin and TAT-Cx43CT overcome the inhibition of $\mathrm{Cx}$ 43-hemichannel responses induced by high $\left[\mathrm{Ca}^{2+}\right]_{\mathrm{i}}$

To further elucidate the mechanism by which the CT tail is involved in regulating $\mathrm{Cx}$ 43-hemichannel activity, we studied ATP release in HeLa and C6 glioma cells ectopically expressing Cx43. Recently De Vuyst et al. (56) demonstrated that Cx43 expressed in C6 or HeLa cells displayed a bell-shaped dependence toward $\left[\mathrm{Ca}^{2+}\right]_{\mathrm{i}}$. By applying different [A23187], it was shown that $\left[\mathrm{Ca}^{2+}\right]_{\mathrm{i}}$ changes with a peak in the 500 $\mathrm{nM}$ range ("medium $\left[\mathrm{Ca}^{2+}\right]_{\mathrm{i}}$ " provoked by $2 \mu \mathrm{M}$ A23187; Fig. 5A) induced Cx43 hemichannelmediated ATP release, whereas ATP release was abolished when $\left[\mathrm{Ca}^{2+}\right]_{\mathrm{i}}$ was elevated to values in the order of 1-2 $\mu \mathrm{M}$ ("high $\left[\mathrm{Ca}^{2+}\right]_{\mathrm{i}}$ " provoked by $10 \mu \mathrm{M}$ A23187; Fig. $5 A$ ), pointing to an inhibitory effect of high $\left[\mathrm{Ca}^{2+}\right]_{\mathrm{i}}$ (56). We wondered whether this inhibition of hemichannel responses by high $\left[\mathrm{Ca}^{2+}\right]_{\mathrm{i}}$ resembled the inhibition of hemichannel responses in BCECs by thrombin and could be overcome by $5 \mu \mathrm{M}(-)$ blebbistatin (a specific inhibitor of myosin II ATPase activity; 57) or by TAT-Cx43CT peptides (Fig. 7A). We anticipated that high $\left[\mathrm{Ca}^{2+}\right]_{\mathrm{i}}$ would trigger actomyosin contractility and in this way inhibit Cx43-hemichannel opening, similar to the effect of thrombin in BCECs, which sensitizes the cells toward $\mathrm{Ca}^{2+}$-induced contractility.

First, pretreatment of Cx43-expressing HeLa cells with (-)-blebbistatin prevented the inhibition of $\mathrm{Cx} 43$ hemichannel-mediated ATP release by high $\left[\mathrm{Ca}^{2+}\right]_{\mathrm{i}}$ (triggered by $10 \mu \mathrm{M}$ A23187), whereas the inactive enantiomer (+)-blebbistatin had no influence (Fig. $7 B)$. Notably, (-)-blebbistatin did not significantly affect the activation of $\mathrm{Cx} 43$ hemichannels by medium $\left[\mathrm{Ca}^{2+}\right]_{\mathrm{i}}$ (triggered by $2 \mu \mathrm{M}$ A23187). These effects were confirmed in Cx43-expressing C6 glioma cells (Supplemental Fig. 4A).

Second, pretreatment of Cx43-expressing HeLa cells with TAT-Cx43CT prevented the inhibition of Cx43hemichannel-mediated ATP release by high $\left[\mathrm{Ca}^{2+}\right]_{\mathrm{i}}$, whereas the TAT-Cx43CTrev control peptide did not (Fig. 7C). Furthermore, these effects appeared to be independent of the interaction of $\mathrm{Cx} 43$ with ZO-1,
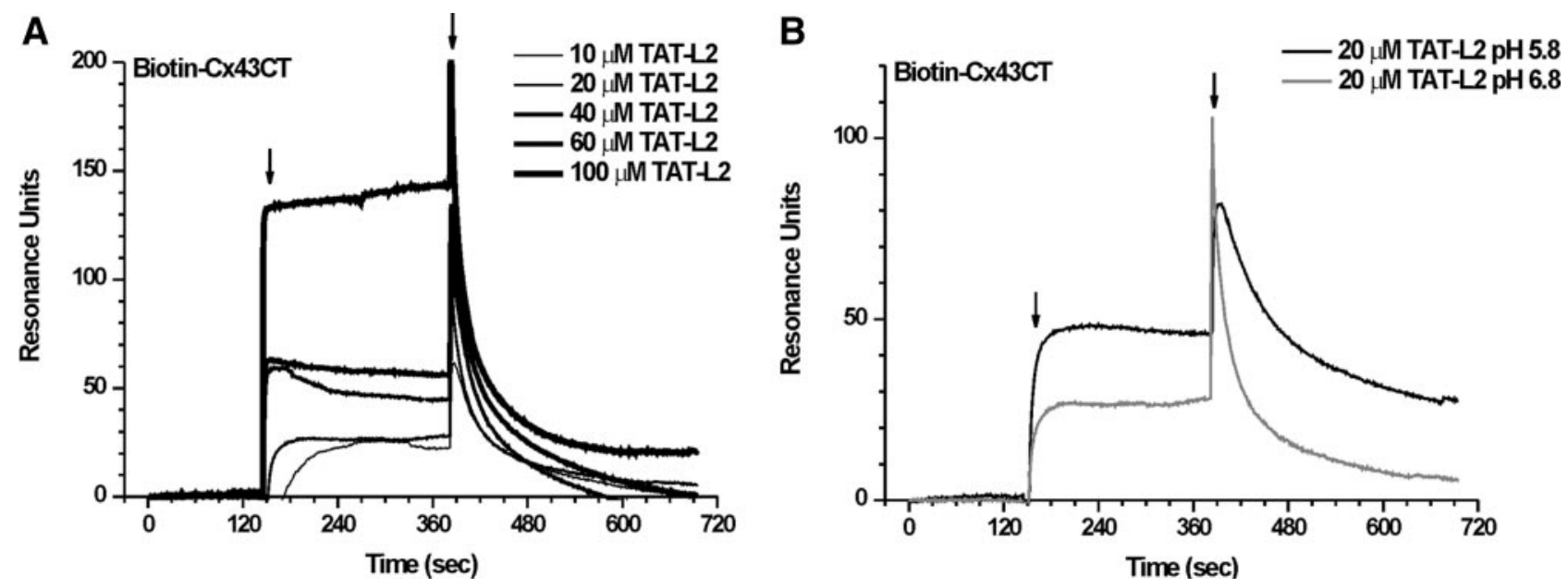

Figure 6. TAT-L2 peptide binds to biotin-Cx43CT immobilized to streptavidin-coated sensor chip. Sensorgrams illustrating the binding of TAT-L2 to biotin-Cx43CT immobilized to a streptavidin-coated sensor chip. Values were corrected for background binding of TAT-L2 to biotin-Cx43CTrev. First and second arrows illustrate the beginning of association and dissociation, respectively. A) Signals increase with increasing TAT-L2 concentrations, indicating a specific binding of TAT-L2 to biotinCx43CT. B) Signals increase by lowering the $\mathrm{pH}$ from 6.8 to 5.8, which favors the $\alpha$-helical structure of the TAT-L2 peptide. Representative experiments from 3 independent experiments are shown. 
A

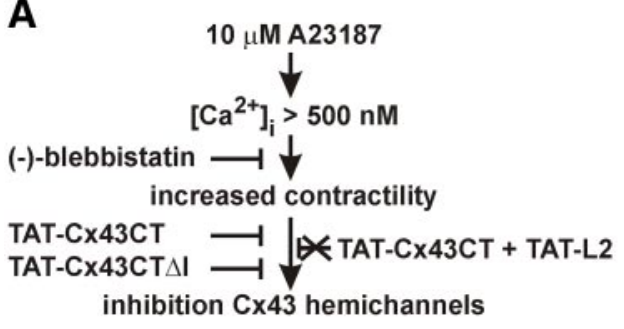

D

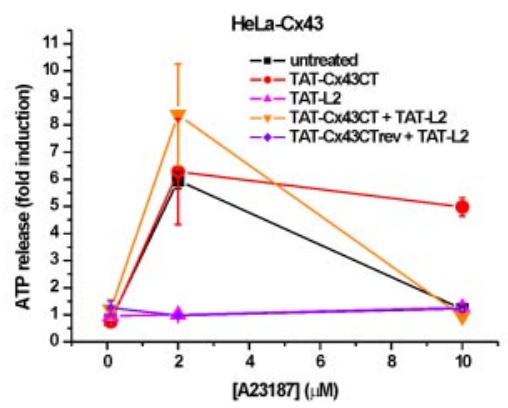

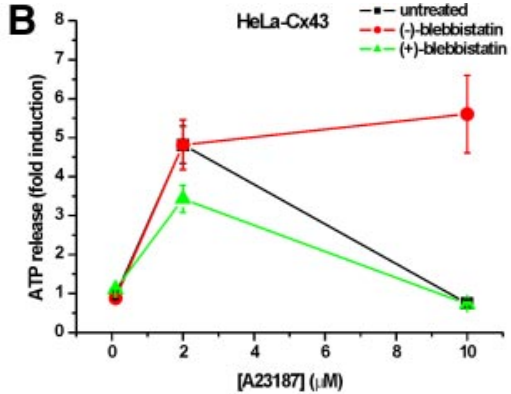

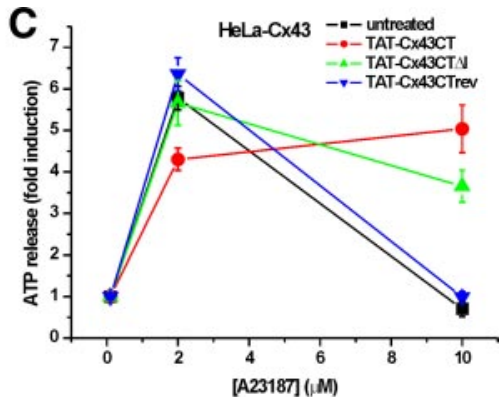

$\mathbf{E}$

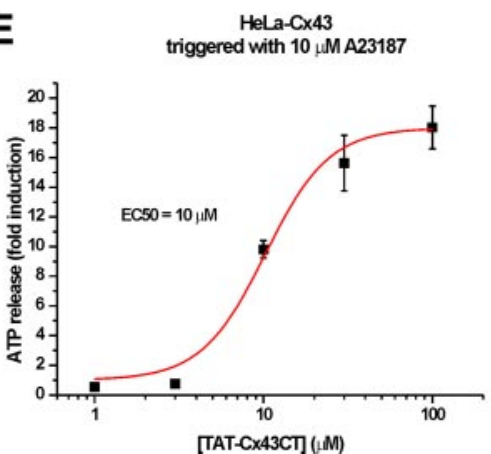

$\mathbf{F}$

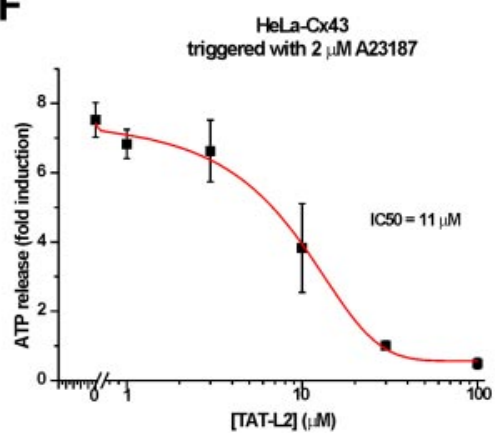

Figure 7. (-)-Blebbistatin as well as TAT-Cx43CT peptides prevent the inhibition of Cx43-mediated ATP release triggered by high $\left[\mathrm{Ca}^{2+}\right]_{\mathrm{i}}$ in HeLa cells ectopically expressing $\mathrm{Cx} 43$. A) Proposed model for the activation of contractility by high $\left[\mathrm{Ca}^{2+}\right]_{\mathrm{i}}$, provoked by $10 \mu \mathrm{M}$ A23187. Action of (-)-blebbistatin and TAT-Cx43CT, TAT-Cx43CTAI, and TAT-Cx43CT + TAT-L2 in this pathway is indicated. $B-D$ ) Quantification of ATP release (fold induction of baseline) in response to different concentrations of A23187 in Cx43-expressing HeLa cells $(n=12)$. Effect of $(-)$-blebbistatin and its inactive enantiomer $(+)$-blebbistatin $(B)$, of different C-terminal TAT peptides $(C)$, and of TAT-L2 alone or coincubated with TAT-Cx43CT $(D)$. E) Dose-response curve for the effect of TAT-Cx43 on the suppression of the inhibition of Cx43-hemichannel-mediated ATP release provoked by $10 \mu \mathrm{M}$ A23187. $F$ ) Dose-response curve for the effect of TAT-L2 on the inhibition of Cx43-hemichannel-mediated ATP release provoked by $2 \mu \mathrm{M}$ A23187.

since TAT-Cx43CTAI also prevented this inhibition. These results were confirmed in Cx43-expressing C6 glioma cells (Supplemental Fig. 4B). Again, there was no effect of the TAT-Cx43CT peptides on the ATP release provoked by $2 \mu \mathrm{M}$ A23187 (medium $\left[\mathrm{Ca}^{2+}\right]_{\mathrm{i}}$ ).

Third, as already shown in Fig. 4C, TAT-L2 and TAT-Cx43CT were able to neutralize and counteract each other (Fig. 7D). As a result, TAT-Cx43CT neutralized the inhibitory effect of TAT-L2 on a Cx43hemichannel opening by medium $\left[\mathrm{Ca}^{2+}\right]_{\mathrm{i}}$ (Fig. $7 D$; compare $\boldsymbol{\Delta}$ with $\boldsymbol{\nabla}$ at $2 \mu \mathrm{M}$ A23187), whereas the TAT-L2 neutralized the ability of TAT-Cx43CT to overcome the inhibition of $\mathrm{Cx} 43$-hemichannel opening by high $\left[\mathrm{Ca}^{2+}\right]_{\mathrm{i}}$ (Fig. $7 D$; compare $\boldsymbol{0}$ with $\boldsymbol{\nabla}$ at $10 \mu \mathrm{M}$ A23187). As a result, in the presence of TAT-L2, TAT-Cx43CT was not able to overcome the inhibition of $\mathrm{Cx} 43$ hemichannel-mediated ATP release, and therefore $\mathrm{Cx} 43$ hemichannel-mediated ATP release was inhibited by high $\left[\mathrm{Ca}^{2+}\right]_{\mathrm{i}}$.

In addition, we measured in Cx43-expressing HeLa cells the dose response for TAT-Cx43CT on ATP release triggered by $10 \mu \mathrm{M}$ A23187 (Fig. 7E) and for TAT-L2 on ATP release triggered by $2 \mu \mathrm{M}$ A23187 (Fig. $7 F$ ). These results indicate that TAT-Cx43CT overcomes the inhibition of $\mathrm{Cx} 43$ hemichannels in response to high $\left[\mathrm{Ca}^{2+}\right]_{\mathrm{i}}$ with an $\mathrm{EC}_{50}$ of $\sim 10 \mu \mathrm{M}$ with a maximal effect at $100 \mu \mathrm{M}$ and that TAT-L2 inhibits medium $\left[\mathrm{Ca}^{2+}\right]_{\mathrm{i}}$-induced $\mathrm{Cx} 43$ hemichannel activity with an $\mathrm{IC}_{50}$ of $\sim 11 \mu \mathrm{M}$ with a maximal effect at $100 \mu \mathrm{M}$. These results indicate that both peptides are taken up with similar efficiencies and interfere with loop/tail interaction with similar affinities. As an additional control, we used TAT-Cx50L2 (100 $\mu \mathrm{M})$. This peptide did not inhibit the $\mathrm{Cx} 43$ hemichannel-mediated ATP release triggered by $2 \mu \mathrm{M}$ A23187 (Supplemental Fig. $3 D)$.

Taken together, these results indicate that contractility and the last $10 \mathrm{CT}$ aa of $\mathrm{Cx} 43$ are involved in the inhibition of $\mathrm{Cx} 43$-hemichannel responses by high $\left[\mathrm{Ca}^{2+}\right]_{\mathrm{i}}$ and that these effects are mediated through the L2 region of $\mathrm{Cx} 43$ hemichannels.

Effect of (-)-blebbistatin on inhibition of Cx43 hemichannels by high $\left[\mathrm{Ca}^{2+}\right]_{\mathrm{i}}$ requires the $\mathrm{CT}$ tail of Cx43

Since inhibition of $\mathrm{Cx} 43$ hemichannel responses by high $\left[\mathrm{Ca}^{2+}\right]_{\mathrm{i}}$ was counteracted by $(-)$-blebbistatin as well as by TAT-Cx43CT, we investigated whether the presence of the CT tail of $\mathrm{Cx} 43$ was required for the effect of (-)-blebbistatin. Therefore, we used HeLa cells expressing $\mathrm{Cx} 43^{\mathrm{M} 239}$, a truncated version of $\mathrm{Cx} 43$ that lacks the complete CT. As shown in previous studies, the CT is essential for Cx43-hemichannel activity $(33,58)$. Here we confirm that in contrast to full-length $\mathrm{Cx} 43$, a rise in $\left[\mathrm{Ca}^{2+}\right]_{\mathrm{i}}$ was not able to provoke ATP release from $\mathrm{Cx} 43^{\mathrm{M} 239}$-expressing HeLa 
cells, indicating that $\mathrm{Cx} 43^{\mathrm{M} 239}$ does not form functional hemichannels (Fig. 8A). Furthermore, pretreatment of the cells with $(-)$-blebbistatin was not able to restore $\mathrm{Cx} 43^{\mathrm{M} 239}$-hemichannel activity. These data indicate that the CT tail of Cx43 is involved in sensing the actomyosin contractility, thereby regulating Cx43-hemichannel activity.

\section{TAT-Cx43CT restores $\mathrm{Cx} 43^{\mathrm{M} 239}$ \\ hemichannel-mediated ATP release}

Because $\mathrm{Cx} 43^{\mathrm{M} 239}$ did not display hemichannel responses on $\left[\mathrm{Ca}^{2+}\right]_{\mathrm{i}}$ increases, we speculated that addition of TAT-Cx43CT could restore its activity. Strikingly, pretreatment of $\mathrm{Cx} 43^{\mathrm{M} 239}$-expressing HeLa cells with TATCx43CT restored ATP release on challenging the cells with $2 \mu$ M A23187 (Fig. 8B). Similar results were obtained with TAT-Cx43CT $\Delta$ I, whereas TAT-Cx43CTrev peptide did not significantly affected ATP release. The restoration of ATP release via $\mathrm{Cx} 43^{\mathrm{M} 239}$ hemichannels by TATCx43CT pretreatment gave a response profile that lacked the typical bell-shaped $\left[\mathrm{Ca}^{2+}\right]_{\mathrm{i}}$ dependence (i.e., it lacked the disappearance of the responses at high $\left[\mathrm{Ca}^{2+}\right]_{\mathrm{i}}$ stimulation). This suggests that residues in the CT tail outside of the region represented by the TAT-Cx43CT peptide are responsible for sensing the increased contractility. Moreover, we found that the action of TAT-Cx43CT on
$\mathrm{Cx} 43^{\mathrm{M} 239}$ hemichannels was neutralized by the presence of TAT-L2. Coincubation of TAT-L2 with TAT-Cx43CT abolished the TAT-Cx43CT-mediated Cx43 ${ }^{\mathrm{M} 239}$. hemichannel activity induced by $2 \mu \mathrm{M}$ A23187 (Fig. 8C). This indicates that TAT-L2 acts as a "scaffold" for TATCx43CT, thereby preventing its stimulatory action on $\mathrm{Cx} 43^{\mathrm{M} 239}$.

We also checked whether TAT-Cx43CT restored $\mathrm{Cx} 43^{\mathrm{M} 239}$-hemichannel activity in response to $\mathrm{Ca}^{2+}$-free solution (Fig. 8D). As previously published (33), $\mathrm{Ca}^{2+}$. free solution did not provoke ATP release in $\mathrm{Cx} 43^{\mathrm{M} 239}$ expressing cells, in contrast to cells expressing wild-type Cx43. However, pretreatment with TAT-Cx43CT restored $\mathrm{Cx} 43^{\mathrm{M} 239}$-hemichannel activity. Again, the effect of TAT-Cx43CT on Cx $43^{\text {M239 }}$ hemichannels was counteracted by coincubation with TAT-L2.

We also determined the dose response for the effect of TAT-Cx43CT on $\mathrm{Cx} 43^{\mathrm{M} 239}$-hemichannel activity in response to $2 \mu \mathrm{M}$ A23187 (Fig. $8 E$ ). These measurements show that TAT-Cx43CT restored $\mathrm{Cx} 43^{\mathrm{M} 239}$-hemichannel activity with an $\mathrm{EC}_{50}$ of $\sim 30 \mu \mathrm{M}$. The highest effect measured was obtained at $100 \mu \mathrm{M}$ TAT-Cx43CT.

Furthermore, we also used this system to monitor the efficiency of uptake of TAT-Cx43CT and TAT-L2 by measuring $\mathrm{Cx} 43^{\mathrm{M} 239}$-hemichannel activity in response to $2 \mu \mathrm{M}$ A23187 from cells pretreated with $100 \mu \mathrm{M}$ of TAT-Cx43CT and different [TAT-L2] (Fig. 8F). The re-
A

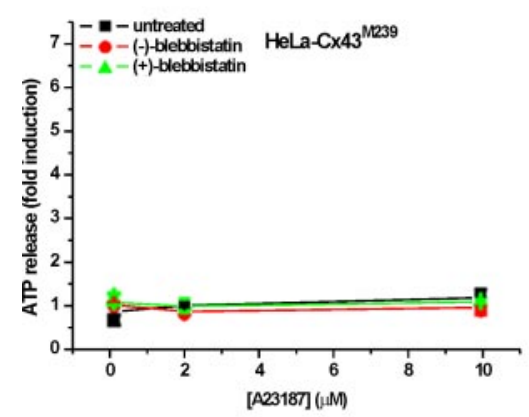

D

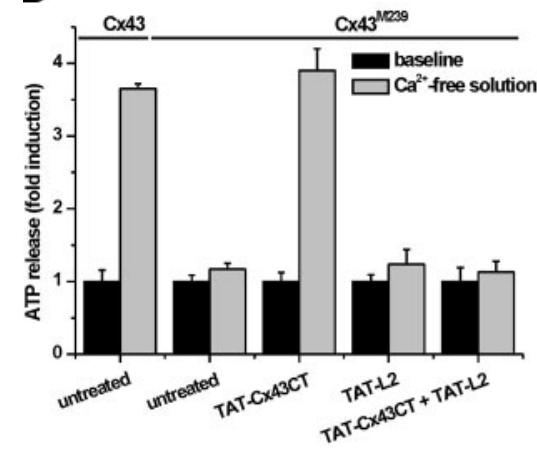

B

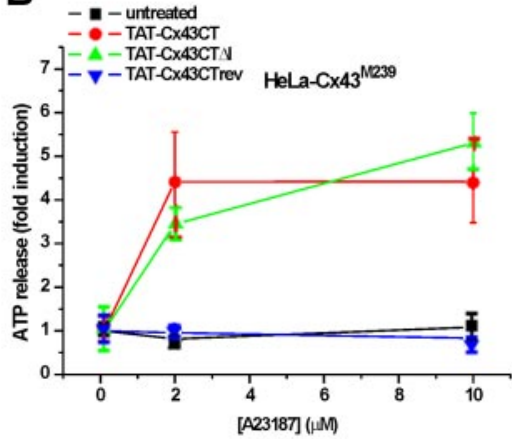

E

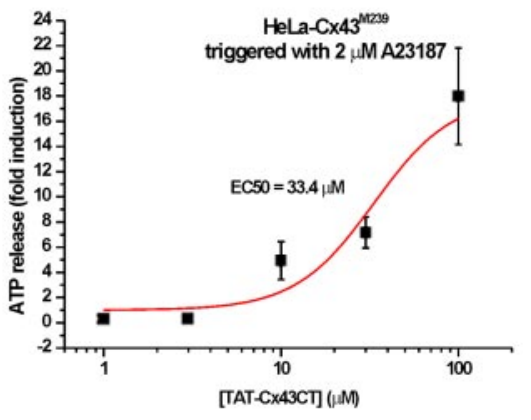

C

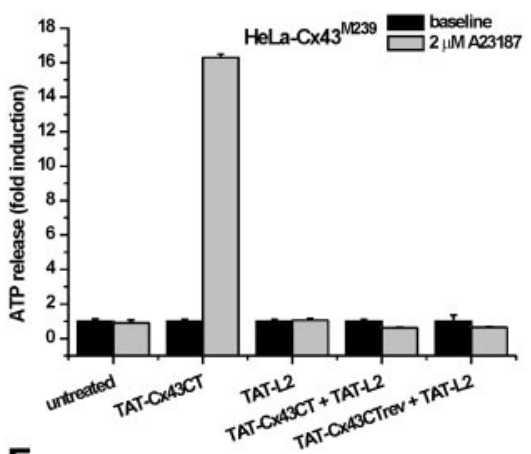

$\mathbf{F}$

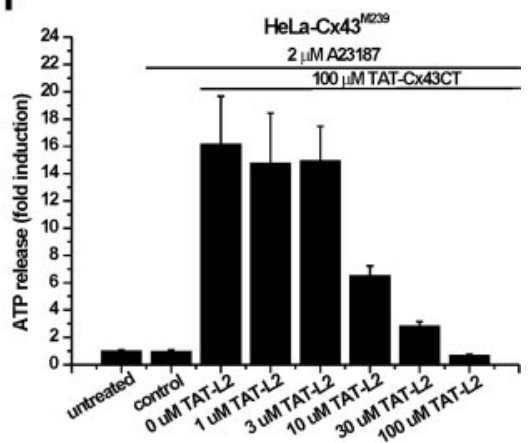

Figure 8. TAT-Cx43CT peptides are sufficient to restore the activity of $\mathrm{Cx} 43^{\mathrm{M} 239}$ hemichannels and are counteracted by the presence of TAT-L2. A, B) Quantification of ATP release in response to different concentrations of A23187 in Cx43 ${ }^{\text {M239. }}$ expressing HeLa cells $(n=12)$. A) Effect of $(-)$-blebbistatin. $B)$ Effect of different TAT-Cx43CT peptides. $C$, $D)$ Effect of TAT-Cx43CT, TAT-L2, TAT-Cx43CT + TAT-L2, and TAT-Cx43CTrev + TAT-L2 on ATP release from Cx43 ${ }^{\text {M239-expressing }}$ HeLa cells triggered by $2 \mu \mathrm{M}$ A23187 $(C)$ or $\mathrm{Ca}^{2+}$-free solution $(D)$. E) Dose-response curve for the effect of TAT-Cx43 on the restoration of $\mathrm{Cx} 43^{\mathrm{M} 239}$-hemichannel-mediated ATP release provoked by $2 \mu \mathrm{M}$ A23187. $F$ ) Effect of increasing [TAT-L2] on the TAT-Cx43CT-restored Cx43 ${ }^{\mathrm{M} 239}$-hemichannel-mediated ATP release in response to $2 \mu \mathrm{M}$ A23187. 
sults show that $100 \mu \mathrm{M}$ TAT-L2 is needed to fully block the effect of $100 \mu \mathrm{M}$ TAT-Cx43CT, suggesting that TATCx43CT and TAT-L2 are taken up with similar efficiencies, leading to equimolar amounts of both peptides in the cell and complete scaffolding of TAT-Cx43CT by TAT-L2.

Finally, we also exploited this system to investigate whether TAT-Cx43CT can affect Cx50 hemichannels. Therefore, we used the loop region of Cx50 corresponding to the L2 region of Cx43 as a TAT-fused peptide (TAT-Cx50L2). Supplemental Fig. 3E shows that TAT-Cx50L2 is not able to prevent the restoration of $\mathrm{Cx} 43^{\mathrm{M} 239}$-hemichannel activity by TAT-Cx43CT in response to $2 \mu \mathrm{M}$ A23187, suggesting that TAT-Cx43CT is unlikely to affect Cx50-hemichannel activity.

Taking together all these results, we conclude that the binding of TAT-Cx43CT to the L2 region of $\mathrm{Cx} 43^{\mathrm{M} 239}$ is essential for restoring hemichannel activity in $\mathrm{Cx} 43^{\mathrm{M} 239}$ by TAT-Cx43CT.

\section{TAT-Cx43CT restores Cx43-hemichannel currents in oocytes}

It is known that Cx43 expressed in Xenopus oocytes does not form functional hemichannels, or at least it is very hard to detect them in electrophysiological experiments (59-61). We hypothesized that the lack of $\mathrm{Cx} 43$ hemichannel activity in Xenopus oocytes may be related to the absence of Cx43-intramolecular interactions. Thus, we anticipated that TAT-Cx43CT peptides may rescue Cx43hemichannel activity in Xenopus oocytes. Therefore, we measured hemichannel currents in oocytes injected with cRNA of $\mathrm{Cx} 43$ and siRNA against Cx38 to knock down endogenous connexins. Under control conditions, small currents were observed $(0.13 \pm 0.11$ $\mu \mathrm{A}$ at $+60 \mathrm{mV}, n=10$ ) (Fig. 9A). However, TATCx43CT peptide increased the outward Cx43hemichannel currents 6.1 times $(0.82 \pm 0.21 \mu \mathrm{A}$ at +60 $\mathrm{mV}, n=9$ ) and provoked a large tail current (Fig. 9B), whereas TAT-Cx43CTrev did not increase these currents $(0.18 \pm 0.13 \mu \mathrm{A}$ at $+60 \mathrm{mV}, n=9)$ and provoked only a small increase of the tail current (Fig. 9C). $I / V$ analyses (Fig. 9D) showed that the currents, potentiated by TAT-Cx43CT, were activated starting from $-10 \mathrm{mV}$ on. The TAT-Cx43CT peptide did not influence the reversal potential (Fig. 9D), suggesting that TATCx43CT increases the open probability.

To assess whether the TAT-Cx43CT-induced hemichannel currents depended on the presence of Cx43, we performed whole-cell voltage-clamp measurements on oocytes that were only injected with siRNA against Cx38 (Fig. 9E, F). Hence, in oocytes lacking ectopic Cx43 expression, no hemichannel-mediated currents were observed (Fig. 9E). Furthermore, TAT-Cx43CT did not provoke any additional hemichannel currents (Fig. $9 F)$. Quantitative analysis of the whole-cell voltage-clamp measurements performed on siCx38-treated oocytes revealed that the currents obtained from the untreated oocytes
A

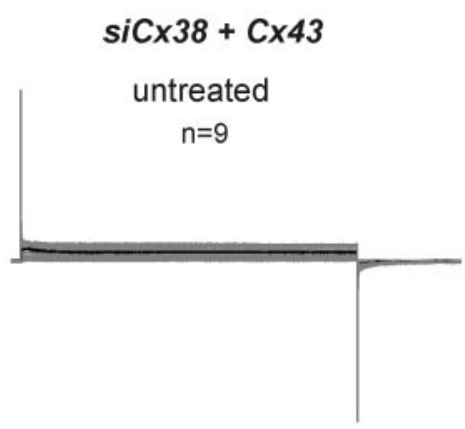

D

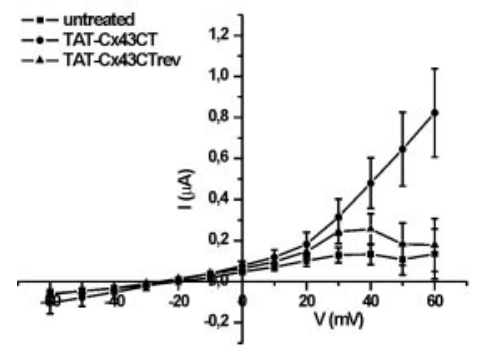

B

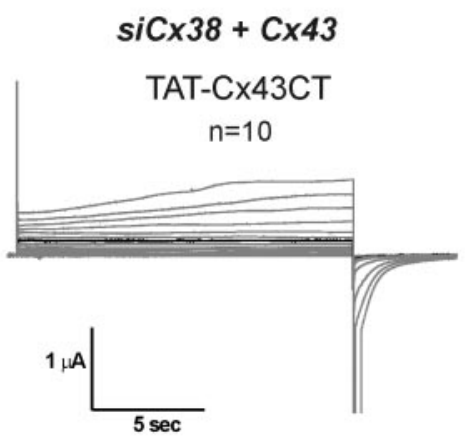

$\mathbf{E}$

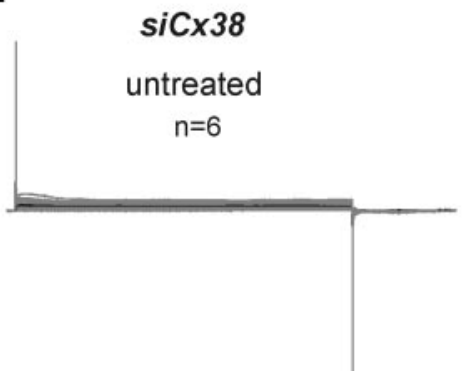

C

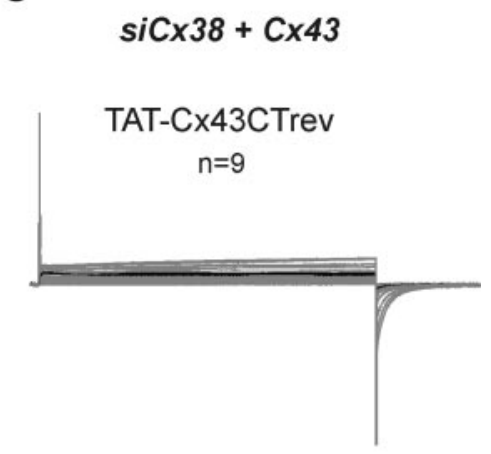

$\mathbf{F}$

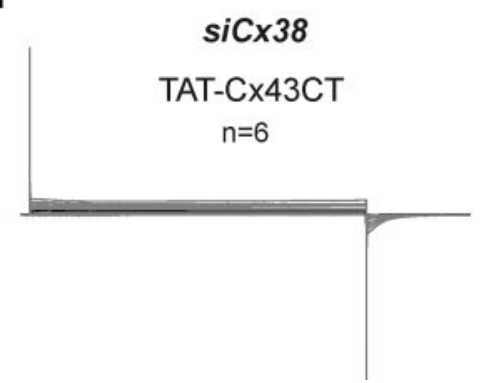

Figure 9. TAT-Cx43CT peptides restore Cx43 hemichannel-mediated currents in Cx43-overexpressing oocytes. A-C) Ttypical whole-cell currents as a function of time in response to $10 \mathrm{mV}$ voltage steps in Cx43-expressing oocytes (gray). Currents obtained at $0 \mathrm{mV}$ are indicated in black. Endogenous Cx38 was knocked down by siRNA. Currents were measured in untreated $(A)$, TAT-Cx43CT-treated $(B)$, and TAT-Cx43CTrev-treated $(C)$ Cx43-expressing oocytes. $D) I / V$ plot for Cx43-expressing oocytes untreated or treated with either TAT-Cx43CT or TAT-CX43CTrev. E, $F$ ) Typical whole-cell currents as a function of time in response to different voltage steps in oocytes only injected with Cx38 siRNA. Currents were measured in untreated $(E)$ and TAT-Cx43CT-treated $(F)$ oocytes. 
did not significantly differ from the currents obtained from the TAT-Cx43CT-treated oocytes $(0.09 \pm 0.04$ and $0.12 \pm 0.11$ $\mu \mathrm{A}$, respectively). This indicates that the TAT-Cx43CTinduced hemichannel currents observed in Cx43-expressing oocytes are mediated through Cx43.

\section{DISCUSSION}

There are 2 major findings in the present study: intramolecular loop/tail interactions are critical for $\mathrm{Cx} 43$ hemichannel activity, and activation of the actomyosin contractile system inhibits Cx43 hemichannels by interfering with these intramolecular loop/tail interactions.

Different observations support this hypothesis: TATCx43CT overcame thrombin-induced inhibition of Cx43hemichannel opening, whereas TAT-L2 caused inhibition of Cx43-hemichannel opening; the inhibitory action of TAT-L2 was abolished by 2 mutations (H126K/I130N) shown to be important for loop/tail interaction; TAT$\mathrm{Cx} 43 \mathrm{CT}$ was sufficient to restore $\left[\mathrm{Ca}^{2+}\right]_{\mathrm{i}}$-induced opening of nonfunctional $\mathrm{Cx} 43^{\mathrm{M} 239}$ hemichannels; biotinCx43CT was sufficient to bind the L2 region of Cx43 in SPR experiments; and the inhibitory action of TAT-L2 on Cx43-hemichannel responses was neutralized by coincubation with TAT-Cx43CT and vice versa. We therefore propose a novel model for the regulation of $\mathrm{Cx} 43$ hemichannel activity by intramolecular protein interaction between the CT tail and the CL, providing novel insights in the cell biological regulation of $\mathrm{Cx} 43$ hemichannels (Fig. 10).

\section{Intercellular communication in primary BCECs is mainly mediated via Cx43 hemichannels}

Although Cx43 forms functional GJs that participate in intercellular propagation of $\mathrm{Ca}^{2+}$ waves in BCECs, previous experiments (28) and new experiments in the current paper demonstrate that intercellular $\mathrm{Ca}^{2+}$-wave propagation in BCECs mainly depends on ATP release via Cx43 hemichannels. Hydrolysis of ATP by application of apyrase resulted in a marked reduction of the $\mathrm{Ca}^{2+}$-wave propagation. In these conditions, application of Cx43 siRNA had no significant effect on $\mathrm{Ca}^{2+}$ wave propagation. On the other hand, application of the ecto-nucleotidase inhibitor ARL-67156 resulted in a very large increase in active area, which was more than 10-fold higher than the active area under conditions when ATP-dependent $\mathrm{Ca}^{2+}$-wave propagation was inhibited by apyrase. Cx43 siRNA reduced that active area in the presence of ARL- 67156 by more than $50 \%$. These results exclude the possibility that a major part of the Cx43 siRNA-inhibition of functional responses is due to reduction of GJ communication.

Although our experiments demonstrated the contribution of Cx43-mediated ATP release to intercellular $\mathrm{Ca}^{2+}$-wave propagation in BCECs, our results also indicate that $\mathrm{Cx} 43$ hemichannels may not be the only pathway responsible for ATP release from these cells, because a nearly complete knockdown of $\mathrm{Cx} 43$ reduces the active area of the $\mathrm{Ca}^{2+}$ wave or the amount of ATP released from these cells by only $\sim 60 \%$. This indicates that other connexin and pannexin hemichannels may be present and contribute to ATP release in these cells. One such candidate is $\mathrm{Cx} 50$, which is highly expressed in the lens of the eye (62). However, although we found Cx50 mRNA in BCECs (52), we could not detect the Cx50 protein in BCEC protein by Western blot analysis. This result confirms an earlier study, reporting that the Cx50 protein could not be detected in the rat corneal endothelial cells, while the Cx50 mRNA was present (63). This suggests that Cx50 is either not present in these cells or present only at very low amounts. Nevertheless, we excluded the contribution of Cx50 in our system by using TAT-Cx50CT and TAT-Cx50L2 peptides, which did not have any effect on $\mathrm{Ca}^{2+}$-wave propagation or on the inhibition of $\mathrm{Ca}^{2+}$-wave propagation by thrombin in these cells. However, Cx26, Cx30.3, Cx32, Cx36, Cx45, Cx46, and Cx46.6 and Panx1, Panx2, and Panx3 could possibly contribute to the $\mathrm{Ca}^{2+}$-wave propagation, because we detected the mRNA of these connexin and pannexin isoforms in BCECs (52). Further studies are needed to document their contribution in the hemichannel-mediated ATP release in BCECs. Preliminary results indicate that pannexins might not be likely to contribute to ATPdependent intercellular communication upon mechanical stimulation of these cells, because low concentrations of carbenoxolone $(5 \mu \mathrm{M})$ reported to inhibit pannexins but not connexin hemichannels at these concentrations $(5,64)$ did not affect the active area of the $\mathrm{Ca}^{2+}$ wave in these cells (unpublished results).

\section{Opening and closing of $\mathrm{Cx} 43$ hemichannel during physiological $\mathrm{Ca}^{2+}$ signaling}

Although several reports document the opening of Cx43 hemichannels during pathophysiological conditions, such as cerebral and cardiac ischemic insults, it remained an open question whether Cx43 hemichannels open during physiological signaling. Therefore, this study together with previous reports indicates that Cx43 hemichannels can be activated by rises in $\left[\mathrm{Ca}^{2+}\right]_{\mathrm{i}}$ in the physiological range. Increasing $\left[\mathrm{Ca}^{2+}\right]_{\mathrm{i}}$ from its resting value of $\sim 100$ to $\sim 300 \mathrm{nM}$ induces a significant opening of Cx43 hemichannels, as measured by ATPrelease experiments. Furthermore, similar findings were obtained for Cx32 (34), indicating that physiological $\mathrm{Ca}^{2+}$ signaling may affect the activity of several types of connexin hemichannels.

Therefore, it is likely that not only pannexin hemichannels, but also Cx43 (and Cx32) hemichannels can open during physiological intracellular $\mathrm{Ca}^{2+}$ signaling, a universal signaling pathway that can be activated in response to growth factors, hormones, signaling molecules (such as ATP), and antibodies that bind to phospholipase $\mathrm{C}_{\beta / \gamma}$-coupled receptors, resulting in opening of inositol 1,4,5-tris phosphate receptors.

Although the opening of Cx43 and Cx32 hemichannels during agonist-induced and mechanical stress- 


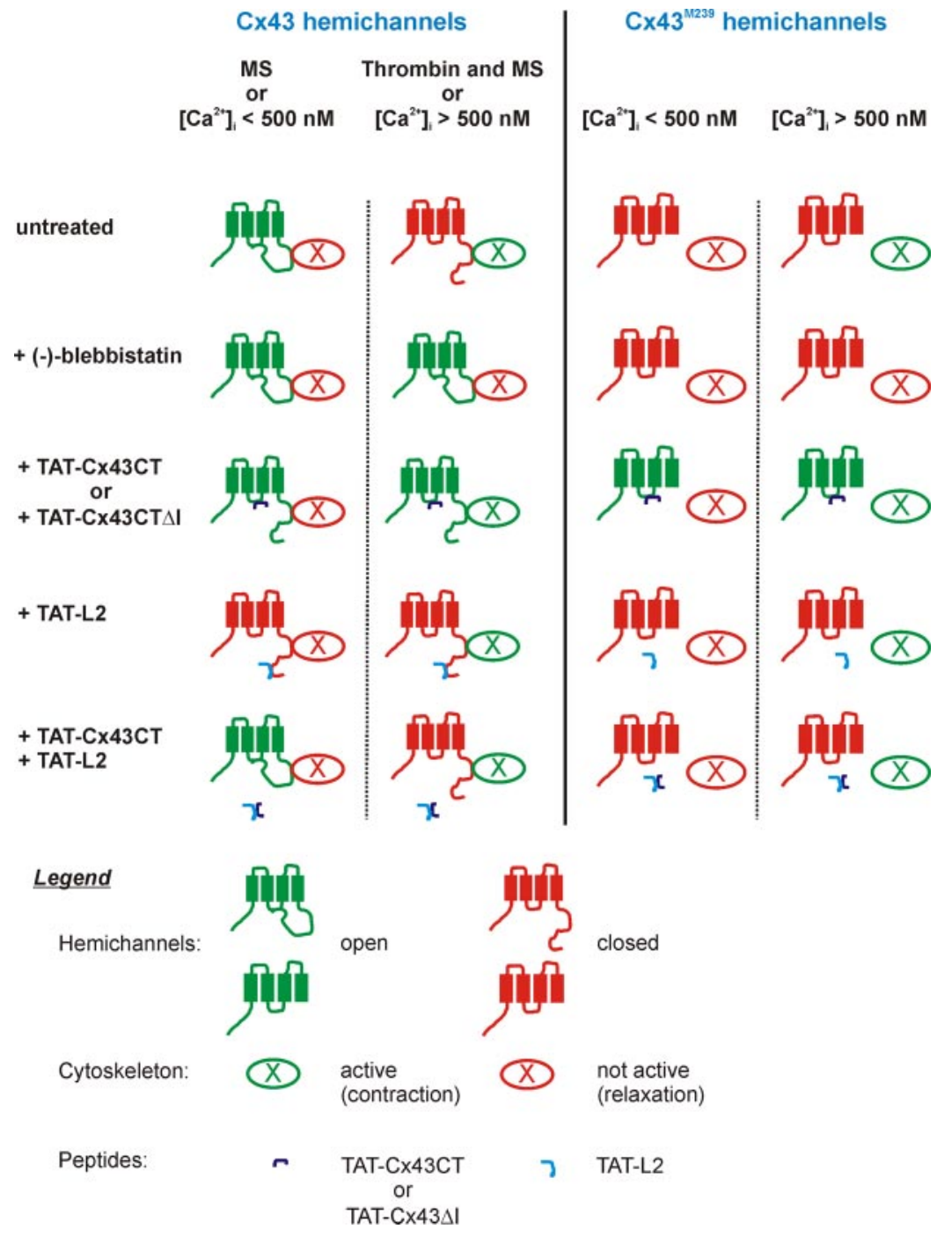

Figure 10. Model for the regulation of $\mathrm{Cx} 43$ and $\mathrm{Cx} 43^{\mathrm{M} 239}$-hemichannel activity by contractility, TAT-Cx43CT and TAT-L2. Left panel: Cx43 hemichannels. We anticipate that functional Cx43 hemichannels possess an intramolecular loop/tail interaction, which is essential for their activity and which is regulated by contractility. Functional opening and closure of Cx43 hemichannels in response to stimuli (given at top) and different drug/peptide treatments (given at left) are depicted in green and red, respectively. The $\mathrm{X}$ protein resembles the actomyosin contractile system. Activation of the actomyosin contractile system is indicated by a red $\mathrm{X}$, whereas conditions in which the actomyosin contractile system is not activated or inhibited (e.g., by (-)-blebbistatin) are indicated by a green $\mathrm{X}$. However, at this moment, it is not known whether the actomyosin directly associates with $\mathrm{Cx} 43$ hemichannels or via a linker protein. See text for further explanation of the model. Right panel: $\mathrm{Cx} 43^{\mathrm{M} 239}$ hemichannels. Addition of $(-)$-blebbistatin does not restore $\mathrm{Cx} 43^{\mathrm{M} 239}$-hemichannel activity, indicating that the regulation of $\mathrm{Cx} 43$-hemichannel activity by contractility requires the presence of the Cterminal tail. Addition of TAT-Cx43CT or TAT$\mathrm{Cx} 43 \mathrm{CT} \Delta \mathrm{I}$ restores $\mathrm{Cx} 43^{\mathrm{M} 239}$-hemichannel activity. Because Cx43CT is able to associate with the intracellular L2 region of $\mathrm{Cx} 43$ and the action of TAT-Cx 43 CT on $\mathrm{Cx} 43^{\mathrm{M} 239}$ is neutralized by the presence of TAT-L2, we hypothesize that TATCx43CT restores $\mathrm{Cx} 43^{\mathrm{M} 239}$-hemichannel activity by binding to the $\mathrm{L} 2$ region. This indicates that a functional $\mathrm{Cx} 43^{\mathrm{M} 239}$ hemichannel requires the intramolecular loop/tail interaction.

induced $\mathrm{Ca}^{2+}$ signaling needs to be explored further, the findings imply that connexin-made hemichannels not only open during pathophysiological conditions, but also may also open during physiological signaling, and that both pannexin-made and connexin-made hemichannels can open during physiological signaling, both contributing to the physiological coordination of processes in a variety of tissues and organs.

In this work, we identified a brake mechanism that prevents the opening of Cx43 hemichannels during $\mathrm{Ca}^{2+}$ signaling. It was already known before that thrombin or high $\left[\mathrm{Ca}^{2+}\right]_{\mathrm{i}}$ increases inhibits Cx43-hemichannel activity (56). We identified activation of the actomyosin contractile system as the mechanism that is responsible for the thrombin-induced inhibition of Cx43-hemichannel activity. This could act as a protective mechanism that prevents excessive opening of Cx43 hemichannels at high $\left[\mathrm{Ca}^{2+}\right]_{\mathrm{i}}$. It remains to be elucidated whether other connexin or pannexin hemichannels are inhibited by the contractile system. In particular, the opening of Cx32 hemichannels may be prevented by the activation of the contractile system in response to high $\left[\mathrm{Ca}^{2+}\right]_{\mathrm{i}}$.

Intramolecular loop/tail interactions are required for Cx43 hemichannel activity and are influenced by the contractile system

We propose that functional Cx43 hemichannels display an intramolecular loop/tail interaction, which is essential for their activity (Fig. 10). Under conditions of mild activation (MS or moderate $\left[\mathrm{Ca}^{2+}\right]_{\mathrm{i}}$ elevation), the actomyosin contractility is not sufficiently increased, and the loop/tail association is not disturbed. Addition of either (-)-blebbistatin or TAT-Cx43CT under these conditions will not affect the activity. However, under conditions of strong activation (either by the presence of thrombin known to sensitize the contractile system to $\mathrm{Ca}^{2+}$ or by strong $\left[\mathrm{Ca}^{2+}\right]_{\mathrm{i}}$ elevation), a strong actomyosin contraction may occur, leading to a physical dislodgement of the tail from the loop and closure of the channel. Blocking actomyosin contractility by inhibiting the myosin II-ATPase activity prevents the physical dislodgement of the tail from the loop, thereby keeping the Cx43 hemichannels open. Finally, we hypothesize that TAT-Cx43CT binds to the L2 region, thereby competing for the endogenous loop/tail interaction, rendering $\mathrm{Cx} 43$ - 
hemichannel activity independent of the endogenous loop/tail interaction and insensitive to enhanced actomyosin contractility. In contrast, treating the cells with TAT-L2 will cause inhibition of Cx43-hemichannel responses, likely by binding to the last 10 aa of the CT tail, thereby disrupting the intramolecular interaction between the CT tail and the endogenous L2 region. Finally, coincubation of TAT-Cx43CT and TAT-L2 will reciprocally neutralize each other's actions on hemichannels, since they act as a scaffold for each other. As a result, neither TAT-Cx43CT nor TAT-L2 will be able to interfere with the endogenous loop/tail interactions, and Cx43 hemichannels will display their normal phenotypic responses. Based on this model, it is tempting to speculate that our data point to a tethering model (65) for the gating of $\mathrm{Cx} 43$ hemichannels, suggesting that contractility acting via cytoskeletal tethers and loop/tail interactions have a major modulating influence on $\mathrm{Cx}$ 43-hemichannel gating. Actomyosin contraction would dislodge the CT tail from the loop and thereby close the channel. However, in addition to contractility, direct effects of $\mathrm{Ca}^{2+}$ on the conformation of the CT and interaction with the intracellular loop of Cx43 have been reported (66) but do not seem sufficient to explain our results, because (-)-blebbistatin could overcome Cx43-hemichannel closure provoked by high $\left[\mathrm{Ca}^{2+}\right]_{\mathrm{i}}$. Furthermore, in this model, we cannot exclude that TAT-Cx43CT peptides may interfere with $\mathrm{Ca}^{2+}$ dependent refolding of the endogenous CT of Cx43 (66). However, the fact that TAT-Cx43CT also restored the activity of $\mathrm{Cx} 43^{\mathrm{M} 239}$ hemichannels that lack the complete CT seems to indicate that effects of TAT-Cx43CT on CT are not involved.

The link between actomyosin cytoskeleton and Cx43 hemichannels can occur either directly or through a yet unidentified linker protein (protein $\mathrm{X}$ in Fig. 10). However, how the CT of Cx43 senses actomyosin contractility remains to be elucidated. At least for Cx43 GJ channels, many proteins of the cytoskeleton or associated with the cytoskeleton have been proposed to interact with $\mathrm{Cx} 43$, including ZO-1 (48), drebrin (67), Src (50), CIP85 (68), CCN3 (69-71), and cortactin (72). To date, it is not known whether these candidate proteins also interact with $\mathrm{Cx} 43$ hemichannels. Nevertheless, we may exclude ZO-1 as a likely candidate, because the effects of TAT-Cx43CT were independent of the last isoleucine residue essential for binding $\mathrm{ZO}-1$, and because $\mathrm{Cx} 43$ hemichannels did not coimmunoprecipitate with $\mathrm{ZO}-1$.

\section{Lack of activity of $\mathrm{Cx} 43^{\mathrm{M} 239}$ hemichannels is due to the absence of loop/tail interactions}

Cx43 ${ }^{\mathrm{M} 239}$, which lacks its CT tail, does not form functional hemichannels at the plasma membrane (Fig. 10). Addition of $(-)$-blebbistatin does not restore $\mathrm{Cx} 43^{\mathrm{M} 239}$ hemichannel activity, indicating that the regulation of Cx43-hemichannel activity by contractility requires its CT tail. Addition of TAT-Cx43CT or TAT-Cx43CT $\Delta \mathrm{I}$ restores $\mathrm{Cx} 43^{\mathrm{M} 239}$-hemichannel activity. Since
Cx43CT is able to associate with the intracellular L2 region of $\mathrm{Cx} 43$, we hypothesize that TAT-Cx43CT restores $\mathrm{Cx} 43^{\mathrm{M} 239}$-hemichannel activity by binding to the L2 region. This hypothesis is supported by the fact that the action of TAT-Cx43CT on Cx43 4239 hemichannel activity is abolished in the presence of TAT-L2. This indicates that functional $\mathrm{Cx} 43^{\mathrm{M} 239}$ hemichannels require the loop/tail interaction and that the last 10 aa of the tail are sufficient to provoke $\mathrm{Cx} 43^{\mathrm{M} 239}$ hemichannel opening in response to hemichannel activators. It is important to note that the association of TATCx43CT with the CL per se is not sufficient to cause Cx43 or $\mathrm{Cx} 43^{\mathrm{M} 239}$-hemichannel opening by itself, but still requires a trigger, such as $\mathrm{MS}, \mathrm{Ca}^{2+}$-free solution, or moderate $\left[\mathrm{Ca}^{2+}\right]_{\mathrm{i}}$ elevations.

\section{$\alpha$-Helical properties of the loop region are important for interaction with the CT of $\mathrm{Cx} 43$}

Our data suggest that the higher-order conformation of the $\mathrm{L} 2$ region is essential for its function as an acceptor for the CT Cx43 residues, because the TAT-L $2^{\mathrm{H} 126 \mathrm{~K} / \mathrm{I1} 0 \mathrm{~N}}$, a peptide variant that has lost its $\alpha$-helical properties and its binding activity to the complete CT tail of $\mathrm{Cx} 43$, was not able to inhibit Cx43 hemichannel responses, and the binding of TAT-L2 to immobilized biotin-Cx43CT was enhanced by lowering the $\mathrm{pH}$, which is known to favor the $\alpha$-helical structure of the L2 region (21). This $\mathrm{pH}-$ dependent regulation of loop/tail interaction has been proposed to be responsible for closure of $\mathrm{Cx} 43 \mathrm{GJ}$ channels (73) and may therefore also be relevant for the increased opening of C43 hemichannels in the context of brain and heart ischemia, in which a decrease in intracellular $\mathrm{pH}$ has been observed $(74,75)$.

\section{Loop/tail interactions differentially regulate $\mathrm{Cx} 43$ GJs and hemichannels}

An important finding emerging from this study is that Cx43-hemichannel responses and GJ coupling are differentially regulated by intramolecular loop/tail interactions. Indeed, it has been shown before that binding of the CT tail (ball) to the CL (receptor) causes inhibition of Cx43 GJs (17-19, 22), whereas in our experiments the binding of the CT tail to the CL comes up as an essential step for rendering Cx43 hemichannels in an activable state. Our data therefore indicate that this intramolecular loop/tail interaction will facilitate the opening of $\mathrm{Cx} 43$ hemichannels in response to known hemichannel stimuli, such as $\mathrm{MS}, \mathrm{Ca}^{2+}$-free solution, moderate $\left[\mathrm{Ca}^{2+}\right]_{\mathrm{i}}$ increase, and membrane depolarization. In agreement with our findings, several reports have indicated that GJs and hemichannels are regulated in opposite ways $(9,76)$. Under inflammatory conditions, cytokines released by microglia have an opposite effect on GJ communication and hemichannel communication in astrocytes (13). Increased intracellular oxidative stress leads to a decreased Cx43mediated GJ communication but to augmented Cx43hemichannel activity $(12,77)$. Cortical astrocytes 
subjected to metabolic inhibition display a decreased Cx43-mediated GJ coupling with an increased $\mathrm{Cx} 43$ hemichannel opening (14). In Cx43-expressing C6 glioma cells, lipopolysaccharide, and basic fibroblast growth factor inhibit GJ coupling, whereas they stimulate hemichannel-mediated ATP release (33). CT tagging of Cx43 with GFP increases the GJ plaque size, enhancing GJ communication $(78,79)$, whereas it hampers the $\mathrm{Cx} 43$ hemichannel-mediated ATP release (58). Cx43 proteins lacking their CT tail were not able to form functional hemichannels $(33,58)$, whereas they are able to form functional GJ channels $(33,80)$. Mutations in $\mathrm{Cx} 43$ (G138R and G143S) that are linked with oculodentodigital dysplasia (ODDD) disrupt GJ coupling, but display increased ATP-releasing hemichannel activity (81). This opposite regulation of hemichannels and GJs may be a cellular strategy to switch between cell-death and cellprotective strategies in cells experiencing severe pathological stimuli, such as ischemic insults or proinflammatory cytokines, or in cells undergoing prosurvival signaling, such as during exposure to lipopolysaccharide and basic fibroblast growth factor.

\section{Physiological and therapeutical importance of loop/tail interactions for Cx43-hemichannel activity}

Our findings provide novel insights into the mechanism by which $\mathrm{Cx}$ 43-hemichannel activity is regulated. In physiological perspective, the inhibition of $\mathrm{Cx} 43$ hemichannel activity by increased contractility may act as a brake on massive Cx43-hemichannel opening, thereby preventing high membrane permeability and the collapse of ionic and metabolic gradients that would be lethal for cells $(7,8)$. Understanding the exact molecular mechanism by which intramolecular loop/tail interactions affect Cx43-hemichannel activity is of fundamental importance to enable rational drug design of small therapeutic molecules that prevent excessive opening of Cx43-hemichannels under pathological conditions. Because excessive Cx43-hemichannel opening during brain or cardiac ischemic insults or inflammation contributes to the collapse of metabolic and energy gradients as well as to the spreading of cell-death factors, the application of small molecules that prevent this opening by interfering with the loop/ tail interactions may be of clinical relevance as a novel therapeutic strategy to reduce or prevent tissue damage. In particular, the importance of the loop region for the control of $\mathrm{Cx} 43$-hemichannel activity is highlighted by the fact that ODDD-associated mutations in the L2 region of $\mathrm{Cx} 43$ lead to either inhibition (e.g., I130T) or stimulation (e.g., G138R, G143S) of Cx43-hemichannel activity (81-84). Therefore, it would be intriguing to investigate whether these mutations affect the binding of L2 to CT and whether changes in loop/tail interactions can account for the altered Cx43-hemichannel activity observed with these ODDD mutations.

The authors thank Dr. Bernd Nilius and Dr. Ludwig Missiaen for critical reading of the paper. This work was supported by Concerted Actions of the K.U. Leuven (grant GOA/09/012) to H.D.S.; by F.W.O. (Fund for Scientific Research Flanders; G.0545.08 to B.H. and J.V.; G.0354.07, G.0140.08, and G.0134.09 to L.L.); by the Interuniversity Attraction Poles Program (Belgian Science Policy; P6/28 to H.D.S. and B.H.; P6/31 to L.L.); and by the Fondecyt de Iniciacion (11080061 to M.R.). The authors do not have any commercial affiliations or conflict of interests.

\section{REFERENCES}

1. Evans, W. H., and Martin, P. E. (2002) Gap junctions: structure and function (Review). Mol. Membr. Biol. 19, 121-136

2. Evans, W. H., De Vuyst, E., and Leybaert, L. (2006) The gap junction cellular internet: connexin hemichannels enter the signalling limelight. Biochem. J. 397, 1-14

3. Scemes, E., Suadicani, S. O., Dahl, G., and Spray, D. C. (2007) Connexin and pannexin mediated cell-cell communication. Neuron Glia Biol. 3, 199-208

4. Scemes, E., Spray, D. C., and Meda, P. (2009) Connexins, pannexins, innexins: novel roles of "hemi-channels." Pflügers Arch. 457, 1207-1226

5. Spray, D. C., Ye, Z. C., and Ransom, B. R. (2006) Functional connexin "hemichannels": a critical appraisal. Glia 54, 758-773

6. Bennett, M. V., Contreras, J. E., Bukauskas, F. F., and Saez, J. C. (2003) New roles for astrocytes: gap junction hemichannels have something to communicate. Trends Neurosci. 26, 610-617

7. Decrock, E., Vinken, M., De Vuyst, E., Krysko, D. V., D’Herde, K., Vanhaecke, T., Vandenabeele, P., Rogiers, V., and Leybaert, L. (2009) Connexin-related signaling in cell death: to live or let die? Cell Death Differ. 16, 524-536

8. Contreras, J. E., Saez, J. C., Bukauskas, F. F., and Bennett, M. V. (2003) Gating and regulation of connexin 43 (Cx43) hemichannels. Proc. Natl. Acad. Sci. U. S. A. 100, 11388-11393

9. Orellana, J. A., Saez, P. J., Shoji, K. F., Schalper, K. A., PalaciosPrado, N., Velarde, V., Giaume, C., Bennett, M. V., and Saez, J. C. (2009) Modulation of brain hemichannels and gap junction channels by pro-inflammatory agents and their possible role in neurodegeneration. Antioxid. Redox Signal. 11, 369-399

10. Clarke, T. C., Williams, O. J., Martin, P. E., and Evans, W. H. (2009) ATP release by cardiac myocytes in a simulated ischaemia model: inhibition by a connexin mimetic and enhancement by an antiarrhythmic peptide. Eur. J. Pharmacol. 605, 9-14

11. Retamal, M. A., Schalper, K. A., Shoji, K. F., Bennett, M. V., and Saez, J. C. (2007) Opening of connexin 43 hemichannels is increased by lowering intracellular redox potential. Proc. Natl. Acad. Sci. U. S. A. 104, 8322-8327

12. Retamal, M. A., Schalper, K. A., Shoji, K. F., Orellana, J. A., Bennett, M. V., and Saez, J. C. (2007) Possible involvement of different connexin43 domains in plasma membrane permeabilization induced by ischemia-reperfusion. J. Membr. Biol. 218, 49-63

13. Retamal, M. A., Froger, N., Palacios-Prado, N., Ezan, P., Saez, P. J., Saez, J. C., and Giaume, C. (2007) Cx43 hemichannels and gap junction channels in astrocytes are regulated oppositely by proinflammatory cytokines released from activated microglia. J. Neurosci. 27, 13781-13792

14. Contreras, J. E., Sanchez, H. A., Eugenin, E. A., Speidel, D. Theis, M., Willecke, K., Bukauskas, F. F., Bennett, M. V., and Saez, J. C. (2002) Metabolic inhibition induces opening of unapposed connexin 43 gap junction hemichannels and reduces gap junctional communication in cortical astrocytes in culture. Proc. Natl. Acad. Sci. U. S. A. 99, 495-500

15. Saez, J. C., Berthoud, V. M., Branes, M. C., Martinez, A. D., and Beyer, E. C. (2003) Plasma membrane channels formed by connexins: their regulation and functions. Physiol. Rev. 83, $1359-1400$

16. Laird, D. W. (2006) Life cycle of connexins in health and disease. Biochem. J. 394, 527-543

17. Morley, G. E., Taffet, S. M., and Delmar, M. (1996) Intramolecular interactions mediate $\mathrm{pH}$ regulation of connexin 43 channels. Biophys. J. 70, 1294-1302

18. Homma, N., Alvarado, J. L., Coombs, W., Stergiopoulos, K., Taffet, S. M., Lau, A. F., and Delmar, M. (1998) A particle- 
receptor model for the insulin-induced closure of connexin43 channels. Circ. Res. 83, 27-32

19. Moreno, A. P., Chanson, M., Elenes, S., Anumonwo, J., Scerri, I., Gu, H., Taffet, S. M., and Delmar, M. (2002) Role of the carboxyl terminal of connexin 43 in transjunctional fast voltage gating. Circ. Res. 90, 450-457

20. Delmar, M., Coombs, W., Sorgen, P., Duffy, H. S., and Taffet, S. M. (2004) Structural bases for the chemical regulation of Connexin43 channels. Cardiovasc. Res. 62, 268-275

21. Duffy, H. S., Sorgen, P. L., Girvin, M. E., O’Donnell, P., Coombs, W., Taffet, S. M., Delmar, M., and Spray, D. C. (2002) pHdependent intramolecular binding and structure involving Cx43 cytoplasmic domains. J. Biol. Chem. 277, 36706-36714

22. Hirst-Jensen, B. J., Sahoo, P., Kieken, F., Delmar, M., and Sorgen, P. L. (2007) Characterization of the pH-dependent interaction between the gap junction protein connexin43 carboxyl terminus and cytoplasmic loop domains. J. Biol. Chem. 282 , 5801-5813

23. Seki, A., Duffy, H. S., Coombs, W., Spray, D. C., Taffet, S. M., and Delmar, M. (2004) Modifications in the biophysical properties of connexin 43 channels by a peptide of the cytoplasmic loop region. Circ. Res. 95, e22-e28

24. Shibayama, J., Gutierrez, C., Gonzalez, D., Kieken, F., Seki, A. Carrion, J. R., Sorgen, P. L., Taffet, S. M., Barrio, L. C., and Delmar, M. (2006) Effect of charge substitutions at residue his-142 on voltage gating of connexin43 channels. Biophys. J. 91, 4054-4063

25. Giepmans, B. N. (2006) Role of connexin43-interacting proteins at gap junctions. Adv. Cardiol. 42, 41-56

26. Herve, J. C., Bourmeyster, N., Sarrouilhe, D., and Duffy, H. S. (2007) Gap junctional complexes: from partners to functions. Prog. Biophys. Mol. Biol. 94, 29-65

27. Laird, D. W. (2010) The gap junction proteome and its relationship to disease. Trends Cell Biol. 20, 92-101

28. Gomes, P., Srinivas, S. P., Van Driessche, W., Vereecke, J., and Himpens, B. (2005) ATP release through connexin hemichannels in corneal endothelial cells. Invest. Ophthalmol. Vis. Sci. 46, 1208-1218

29. Gomes, P., Srinivas, S. P., Vereecke, J., and Himpens, B. (2005) ATP-dependent paracrine intercellular communication in cultured bovine corneal endothelial cells. Invest. Ophthalmol. Vis. Sci. 46, 104-113

30. Omori, Y., and Yamasaki, H. (1999) Gap junction proteins connexin32 and connexin43 partially acquire growth-suppressive function in HeLa cells by deletion of their C-terminal tails. Carcinogenesis 20, 1913-1918

31. Zhu, D., Caveney, S., Kidder, G. M., and Naus, C. C. (1991) Transfection of C6 glioma cells with connexin 43 cDNA: analysis of expression, intercellular coupling, and cell proliferation. Proc. Natl. Acad. Sci. U. S. A. 88, 1883-1887

32. Iyer, S., Deutsch, K., Yan, X., and Lin, B. (2007) Batch RNAi selector: a standalone program to predict specific siRNA candidates in batches with enhanced sensitivity. Comput. Methods Programs Biomed. 85, 203-209

33. De Vuyst, E., Decrock, E., De Bock, M., Yamasaki, H., Naus, C. C., Evans, W. H., and Leybaert, L. (2007) Connexin hemichannels and gap junction channels are differentially influenced by lipopolysaccharide and basic fibroblast growth factor. Mol. Biol. Cell. 18, 34-46

34. De Vuyst, E., Decrock, E., Cabooter, L., Dubyak, G. R., Naus, C. C., Evans, W. H., and Leybaert, L. (2006) Intracellular calcium changes trigger connexin 32 hemichannel opening. EMBO J. 25, 34-44

35. D'hondt, C., Ponsaerts, R., Srinivas, S. P., Vereecke, J., and Himpens, B. (2007) Thrombin inhibits intercellular calcium wave propagation in corneal endothelial cells by modulation of hemichannels and gap junctions. Invest. Ophthalmol. Vis. Sci. 48, $120-133$

36. D'hondt, C., Srinivas, S. P., Vereecke, J., and Himpens, B. (2007) Adenosine opposes thrombin-induced inhibition of intercellular calcium wave in corneal endothelial cells. Invest. Ophthalmol. Vis. Sci. 48, 1518-1527

37. Ponsaerts, R., D'hondt, C., Bultynck, G., Srinivas, S. P., Vereecke, J., and Himpens, B. (2008) The myosin II ATPase inhibitor blebbistatin prevents thrombin-induced inhibition of intercellular calcium wave propagation in corneal endothelial cells. Invest. Ophthalmol. Vis. Sci. 49, 4816-4827
38. Grootjans, J. J., Reekmans, G., Ceulemans, H., and David, G. (2000) Syntenin-syndecan binding requires syndecan-synteny and the co-operation of both PDZ domains of syntenin. J. Biol. Chem. 275, 19933-19941

39. Retamal, M. A., Yin, S., Altenberg, G. A., and Reuss, L. (2009) Modulation of $\mathrm{Cx} 46$ hemichannels by nitric oxide. Am. J. Physiol. Cell. Physiol. 296, C1356-C1363

40. Levesque, S. A., Lavoie, E. G., Lecka, J., Bigonnesse, F., and Sevigny, J. (2007) Specificity of the ecto-ATPase inhibitor ARI 67156 on human and mouse ectonucleotidases. Br. J. Pharmacol. 152, 141-150

41. Li, H., Liu, T. F., Lazrak, A., Peracchia, C., Goldberg, G. S., Lampe, P. D., and Johnson, R. G. (1996) Properties and regulation of gap junctional hemichannels in the plasma membranes of cultured cells. J. Cell Biol. 134, 1019-1030

42. Verselis, V. K., and Srinivas, M. (2008) Divalent cations regulate connexin hemichannels by modulating intrinsic voltage-dependent gating. J. Gen. Physiol. 132, 315-327

43. Thimm, J., Mechler, A., Lin, H., Rhee, S., and Lal, R. (2005) Calcium-dependent open/closed conformations and interfacial energy maps of reconstituted hemichannels. J. Biol. Chem. $\mathbf{2 8 0}$ $10646-10654$

44. Ye, Z. C., Wyeth, M. S., Baltan-Tekkok, S., and Ransom, B. R. (2003) Functional hemichannels in astrocytes: a novel mechanism of glutamate release. J. Neurosci. 23, 3588-3596

45. Toyofuku, T., Yabuki, M., Otsu, K., Kuzuya, T., Hori, M., and Tada, M. (1998) Direct association of the gap junction protein connexin-43 with ZO-1 in cardiac myocytes. J. Biol. Chem. 273 , 12725-12731

46. Hunter, A. W., Barker, R. J., Zhu, C., and Gourdie, R. G. (2005) Zonula occludens-1 alters connexin43 gap junction size and organization by influencing channel accretion. Mol. Biol. Cell. 16, 5686-5698

47. Derangeon, M., Bourmeyster, N., Plaisance, I., Pinet-Charvet, C., Chen, Q., Duthe, F., Popoff, M. R., Sarrouilhe, D., and Herve, J. C. (2008) RhoA GTPase and F-actin dynamically regulate the permeability of $\mathrm{Cx} 43$-made channels in rat cardiac myocytes. J. Biol. Chem. 283, 30754-30765

48. Giepmans, B. N., and Moolenaar, W. H. (1998) The gap junction protein connexin43 interacts with the second PDZ domain of the zona occludens-1 protein. Curr. Biol. 8, 931-934

49. Toyofuku, T., Akamatsu, Y., Zhang, H., Kuzuya, T., Tada, M., and Hori, M. (2001) c-Src regulates the interaction between connexin-43 and ZO-1 in cardiac myocytes. J. Biol. Chem. 276, 1780-1788

50. Sorgen, P. L., Duffy, H. S., Sahoo, P., Coombs, W., Delmar, M., and Spray, D. C. (2004) Structural changes in the carboxyl terminus of the gap junction protein connexin43 indicates signaling between binding domains for c-Src and zonula occludens-1. J. Biol. Chem. 279, 54695-54701

51. Gump, J. M., and Dowdy, S. F. (2007) TAT transduction: the molecular mechanism and therapeutic prospects. Trends Mol. Med. 13, 443-448

52. Ponsaerts, R., D'hondt, C., Gomes, P., Bultynck, G., Srinivas, S., Vereecke, J., and Himpens, B. (2010) ATP release via connexin hemichannels controls intercellular propagation of calcium waves in corneal endothelial cells. In Extracellular ATP and Adenosine as Regulators of Endothelial Cell Function (Gerasimovskaya, E., and Kaczmarek, E., eds) pp. 161-196, Springer Science, New York

53. Giepmans, B. N., Verlaan, I., and Moolenaar, W. H. (2001) Connexin-43 interactions with ZO-1 and alpha- and beta-tubulin. Cell. Commun. Adhes. 8, 219-223

54. Flores, C. E., Li, X., Bennett, M. V., Nagy, J. I., and Pereda, A. E. (2008) Interaction between connexin35 and zonula occludens-1 and its potential role in the regulation of electrical synapses. Proc. Natl. Acad. Sci. U. S. A. 105, 12545-12550

55. Bouvier, D., Kieken, F., Kellezi, A., and Sorgen, P. L. (2008) Structural changes in the carboxyl terminus of the gap junction protein connexin 40 caused by the interaction with c-Src and zonula occludens-1. Cell. Commun. Adhes. 15, 107-118

56. De Vuyst, E., Wang, N., Decrock, E., De Bock, M., Vinken, M., Van Moorhem, M., Lai, C., Culot, M., Rogiers, V., Cecchelli, R., Naus, C. C., Evans, W. H., and Leybaert, L. (2009) $\mathrm{Ca}^{2+}$ regulation of connexin 43 hemichannels in C6 glioma and glial cells. Cell Calcium 46, 176-187

57. Limouze, J., Straight, A. F., Mitchison, T., and Sellers, J. R. (2004) Specificity of blebbistatin, an inhibitor of myosin II. J. Muscle Res. Cell. Motil. 25, 337-341 
58. Kang, J., Kang, N., Lovatt, D., Torres, A., Zhao, Z., Lin, J., and Nedergaard, M. (2008) Connexin 43 hemichannels are permeable to ATP. J. Neurosci. 28, 4702-4711

59. Bao, X., Chen, Y., Reuss, L., and Altenberg, G. A. (2004) Functional expression in Xenopus oocytes of gap-junctional hemichannels formed by a cysteine-less connexin 43. J. Biol. Chem. 279, 9689-9692

60. White, T. W., Deans, M. R., O'Brien, J., Al-Ubaidi, M. R., Goodenough, D. A., Ripps, H., and Bruzzone, R. (1999) Functional characteristics of skate connexin35, a member of the gamma subfamily of connexins expressed in the vertebrate retina. Eur. J. Neurosci. 11, 1883-1890

61. Bao, X., Altenberg, G. A., and Reuss, L. (2004) Mechanism of regulation of the gap junction protein connexin 43 by protein kinase C-mediated phosphorylation. Am. J. Physiol. Cell. Physiol. 286, C647-C654

62. Konig, N., and Zampighi, G. A. (1995) Purification of bovine lens cell-to-cell channels composed of connexin44 and connexin50. J. Cell Sci. 108(Pt. 9), 3091-3098

63. Laux-Fenton, W. T., Donaldson, P. J., Kistler, J., and Green, C. R. (2003) Connexin expression patterns in the rat cornea: molecular evidence for communication compartments. Cornea 22, 457-464

64. Suadicani, S. O., Brosnan, C. F., and Scemes, E. (2006) P2X7 receptors mediate ATP release and amplification of astrocytic intercellular $\mathrm{Ca}^{2+}$ signaling. J. Neurosci. 26, 1378-1385

65. Hamill, O. P., and Martinac, B. (2001) Molecular basis of mechanotransduction in living cells. Physiol. Rev. 81, 685-740

66. Liu, F., Arce, F. T., Ramachandran, S., and Lal, R. (2006) Nanomechanics of hemichannel conformations: connexin flexibility underlying channel opening and closing. J. Biol. Chem. 281, 23207-23217

67. Butkevich, E., Hulsmann, S., Wenzel, D., Shirao, T., Duden, R., and Majoul, I. (2004) Drebrin is a novel connexin-43 binding partner that links gap junctions to the submembrane cytoskeleton. Curr. Biol. 14, 650-658

68. Lan, Z., Kurata, W. E., Martyn, K. D., Jin, C., and Lau, A. F. (2005) Novel rab GAP-like protein, CIP85, interacts with connexin43 and induces its degradation. Biochemistry 44, 2385-2396

69. Sin, W. C., Bechberger, J. F., Rushlow, W. J., and Naus, C. C. (2008) Dose-dependent differential upregulation of CCN1/ Cyr61 and CCN3/NOV by the gap junction protein Connexin43 in glioma cells. J. Cell. Biochem. 103, 1772-1782

70. Fu, C. T., Bechberger, J. F., Ozog, M. A., Perbal, B., and Naus, C. C. (2004) CCN3 (NOV) interacts with connexin43 in C6 glioma cells: possible mechanism of connexin-mediated growth suppression. J. Biol. Chem. 279, 36943-36950

71. Gellhaus, A., Dong, X., Propson, S., Maass, K., Klein-Hitpass, L., Kibschull, M., Traub, O., Willecke, K., Perbal, B., Lye, S. J., and Winterhager, E. (2004) Connexin43 interacts with NOV: a possible mechanism for negative regulation of cell growth in choriocarcinoma cells. J. Biol. Chem. 279, 36931-36942

72. Vitale, M. L., Akpovi, C. D., and Pelletier, R. M. (2009) Cortactin/ tyrosine-phosphorylated cortactin interaction with connexin 43 in mouse seminiferous tubules. Microsc. Res. Tech. 72, 856-867

73. Duffy, H. S., Ashton, A. W., O’Donnell, P., Coombs, W., Taffet, S. M., Delmar, M., and Spray, D. C. (2004) Regulation of connexin43 protein complexes by intracellular acidification. Circ. Res. 94, 215-222

74. Owens, L. M., Fralix, T. A., Murphy, E., Cascio, W. E., and Gettes, L. S. (1996) Correlation of ischemia-induced extracellular and intracellular ion changes to cell-to-cell electrical uncoupling in isolated blood-perfused rabbit hearts. Experimental Working Group. Circulation 94, 10-13

75. Yokota, H., Yamamoto, Y., Naoe, Y., Fuse, A., Sato, H., Unemoto, K., and Kurokawa, A. (2000) Measurements of cortical cellular $\mathrm{pH}$ by intracranial tonometer in severe head injury. Crit. Care Med. 28, 3275-3280

76. Contreras, J. E., Sanchez, H. A., Veliz, L. P., Bukauskas, F. F. Bennett, M. V., and Saez, J. C. (2004) Role of connexin-based gap junction channels and hemichannels in ischemia-induced cell death in nervous tissue. Brain Res. Brain Res. Rev. 47, 290-303

77. Retamal, M. A., Cortes, C. J., Reuss, L., Bennett, M. V., and Saez, J. C. (2006) S-nitrosylation and permeation through connexin 43 hemichannels in astrocytes: induction by oxidant stress and reversal by reducing agents. Proc. Natl. Acad. Sci. U. S. A. 103, 4475-4480

78. Hunter, A. W., Jourdan, J., and Gourdie, R. G. (2003) Fusion of GFP to the carboxyl terminus of connexin43 increases gap junction size in HeLa cells. Cell. Commun. Adhes. 10, 211-214

79. Bukauskas, F. F., Jordan, K., Bukauskiene, A., Bennett, M. V., Lampe, P. D., Laird, D. W., and Verselis, V. K. (2000) Clustering of connexin 43-enhanced green fluorescent protein gap junction channels and functional coupling in living cells. Proc. Natl. Acad. Sci. U. S. A. 97, 2556-2561

80. Maass, K., Shibayama, J., Chase, S. E., Willecke, K., and Delmar, M. (2007) C-terminal truncation of connexin43 changes number, size, and localization of cardiac gap junction plaques. Circ. Res. 101, 1283-1291

81. Dobrowolski, R., Sommershof, A., and Willecke, K. (2007) Some oculodentodigital dysplasia-associated Cx43 mutations cause increased hemichannel activity in addition to deficient gap junction channels. J. Membr. Biol. 219, 9-17

82. Dobrowolski, R., Sasse, P., Schrickel, J. W., Watkins, M., Kim, J. S., Rackauskas, M., Troatz, C., Ghanem, A., Tiemann, K., Degen, J., Bukauskas, F. F., Civitelli, R., Lewalter, T., Fleischmann, B. K., and Willecke, K. (2008) The conditional connexin43G138R mouse mutant represents a new model of hereditary oculodentodigital dysplasia in humans. Hum. Mol. Genet. 17, 539-554

83. Kalcheva, N., Qu, J., Sandeep, N., Garcia, L., Zhang, J., Wang, Z., Lampe, P. D., Suadicani, S. O., Spray, D. C., and Fishman, G. I. (2007) Gap junction remodeling and cardiac arrhythmogenesis in a murine model of oculodentodigital dysplasia. Proc. Natl. Acad. Sci. U. S. A. 104, 20512-20516

84. Lai, A., Le, D. N., Paznekas, W. A., Gifford, W. D., Jabs, E. W., and Charles, A. C. (2006) Oculodentodigital dysplasia connexin 43 mutations result in non-functional connexin hemichannels and gap junctions in C6 glioma cells. J. Cell Sci. 119, 532-541

Received for publication January 6, 2010. Accepted for publication June 24, 2010. 